\title{
Myostatin is a key mediator between energy metabolism and endurance capacity of skeletal muscle
}

Article

Accepted Version

Mouisel, E., Relizani, K., Mille-Hamard, L., Denis, R., Hourde, C., Agbulut, O., Patel, K., Arandel, L., Morales-Gonzalez, S., Vignaud, A., Garcia, L., Ferry, A., Luquet, S., Billat, V., Ventura-Clapier, R., Schuelke, M. and Amthor, H. (2014) Myostatin is a key mediator between energy metabolism and endurance capacity of skeletal muscle. American Journal of Physiology: Regulatory Integrative and Comparative Physiology, 307 (4). R444-R454. ISSN 0363-6119 doi: https://doi.org/10.1152/ajpregu.00377.2013 Available at https://centaur.reading.ac.uk/46308/

It is advisable to refer to the publisher's version if you intend to cite from the work. See Guidance on citing.

Published version at: http://ajpregu.physiology.org/content/307/4/R444

To link to this article DOI: http://dx.doi.org/10.1152/ajpregu.00377.2013

Publisher: American Physiological Society

All outputs in CentAUR are protected by Intellectual Property Rights law, including copyright law. Copyright and IPR is retained by the creators or other copyright holders. Terms and conditions for use of this material are defined in the End User Agreement. 


\section{www.reading.ac.uk/centaur}

\section{CentAUR}

Central Archive at the University of Reading

Reading's research outputs online 


\section{Myostatin is a key mediator between energy metabolism and endurance capacity of skeletal muscle}

Etienne Mouisel $^{1,2}$, Karima Relizani ${ }^{3,4}$, Laurence Mille-Hamard ${ }^{5}$, Raphaël Denis ${ }^{6}$, Christophe Hourdé $^{2,7}$, Onnik Agbulut ${ }^{8}$, Ketan Patel ${ }^{9}$, Ludovic Arandel ${ }^{2}$, Susanne Morales-Gonzalez ${ }^{3}$, Alban Vignaud ${ }^{10}$, Luis Garcia ${ }^{4,11}$, Arnaud Ferry ${ }^{2,12}$, Serge Luquet $^{6,13}$, Véronique Billat ${ }^{5}$, Renée Ventura-Clapier $^{14}$, Markus Schuelke ${ }^{3}$ and Helge Amthor ${ }^{2,4,11}$

${ }^{1}$ INSERM/Paul Sabatier University, UMR1048, Institute of Metabolic and Cardiovascular Diseases, Obesity Research Laboratory, Toulouse, France.

${ }^{2}$ Sorbonne Universités, UPMC Univ Paris 06, Myology Center of Research and Inserm, UMRS974 and CNRS, FRE3617 and Institut de Myologie, F-75013, Paris, France.

${ }^{3}$ Department of Neuropediatrics and NeuroCure Clinical Research Center, Charité Universitätsmedizin Berlin, 13353 Berlin, Germany.

"Laboratoire "End:icap", UFR des Sciences de la Santé, Université de Versailles SaintQuentin-en-Yvelines, France.

${ }^{5}$ INSERM U 902, Université d'Evry-Val d'Essonne, Evry, France.

${ }^{6}$ Université Paris Diderot, Sorbonne Paris Cité, Unité de Biologie Fonctionnelle et Adaptative, CNRS EAC 4413, F-75205 Paris, France.

${ }^{7}$ Laboratory of Exercise Physiology, University of Savoie, Chambery, France.

${ }^{8}$ UPMC Univ Paris 06, Sorbonne Universités, UMR CNRS 8256, Biological Adaptation and Ageing, Paris, F-75005 France.

${ }^{9}$ School of Biological Sciences, University of Reading, Reading, UK.

${ }^{10}$ Généthon, 1 bis rue de l'Internationale, 91002 Evry, France.

${ }^{11}$ Laboratoire LIA-BAHN, Centre Scientifique Monaco, 98000 Monaco, MC.

${ }^{12}$ Université Paris Descartes, 75006 Paris, France.

${ }^{13}$ Centre National de la Recherche Scientifique-CNRS EAC 4413, F-75205 Paris, France.

${ }^{14}$ INSERM U 769, Université Paris-Sud, Châtenay-Malabry, France.

\section{Correspondence should be addressed to:}

Helge Amthor, MD, PhD

Laboratoire «End:icap»

UFR des Sciences de la Santé «Simone Veil»

Université de Versailles Saint-Quentin-en-Yvelines

2 , avenue de la Source de la Bièvre

78180 Montigny-le-Bretonneux, France

Email: helge.amthor@uvsq.fr 


\section{SUMMARY}

Myostatin (Mstn) participates in the regulation of skeletal muscle size and emerges as a regulator of muscle metabolism. We here hypothesized that lack of myostatin profoundly depresses oxidative phosphorylation dependent muscle function. For this extent, we explored $\mathrm{Mstn}^{-/-}$mice as a model for the constitutive absence of myostatin and AAV-mediated overexpression of myostatin propeptide as a model of myostatin blockade in adult wildtype mice. We show that muscles from $\mathrm{Mstn}^{-/}$mice, although larger and stronger, fatigue extremely rapidly. Myostatin deficiency shifts muscle from aerobic towards anaerobic energy metabolism as evidenced by decreased mitochondrial respiration, reduced expression of PPAR transcriptional regulators, increased enolase activity, and exercise induced lactic acidosis. In consequence, constitutively reduced myostatin signaling diminishes exercise capacity, while the hypermuscular state of $\mathrm{Mstn}^{-/-}$mice increases oxygen consumption and the energy cost of running. We wondered whether these results are the mere consequence of the congenital fiber-type switch towards a glycolytic phenotype of constitutive Mstn ${ }^{-/}$mice. Hence we over-expressed myostatin propeptide in adult mice, which did not affect fiber-type distribution, while nonetheless causing increased muscle fatigability, diminished exercise capacity and decreased Pparb/d and Pgc1a expression. In conclusion, our results suggest that myostatin endows skeletal muscle with high oxidative capacity and low fatigability, thus regulating the delicate balance between muscle mass, muscle force, energy metabolism and endurance capacity.

\section{KEYWORDS}

myostatin, exercise capacity, muscle fatigue, oxidative phosphorylation, mitochondria, PPAR 


\section{INTRODUCTION}

Skeletal muscle has inbuilt control mechanisms to prevent overgrowth, which are executed at least in part by secreted molecules of the transforming growth factor- $\beta$ (TGF- $\beta$ ) family, the most important being myostatin (Mstn). Suppression of myostatin signaling stimulates muscle growth, however, the functional benefits arising from myostatin deficiency remain under debate, because the larger muscles of myostatin knockout mice lose specific force $(4,28,34$, 40). On the other hand, a heterozygous Mstn-mutation in racing dogs (whippets) increases performance in short distance races (37), which could be explained by a fiber-type conversion from oxidative to glycolytic phenotype. Previous work suggested that such profound fiber-type conversion in the absence of myostatin negatively alters muscle exercise behavior, fatigability and muscle mitochondrial function $(6,15,18,29,39,42)$. However, a direct effect of myostatin on muscle metabolism has not yet conclusively been established despite increasing evidence for the impact of TGF- $\beta /$ Smad signaling on energy homeostasis $(9,13,32$, 47). Moreover, the question remains open, whether previously observed metabolic and functional changes are the mere consequence of congenital fiber-type conversion following constitutive lack of myostatin or whether myostatin regulates muscle metabolism directly. Here we hypothesized myostatin to regulate oxidative phosphorylation dependent muscle function and that this would be independent of the muscle fiber-type composition. We first investigated in detail the muscle contractile, metabolic and functional characteristics of constitutive $\mathrm{Mstn}^{-/}$mice and found a profound deficit of aerobic exercise capacity. We then compared this phenotype to the effect of myostatin blockade in adult muscle and likewise found an increased fatigability and reduced capacity for aerobic exercise following overexpression of myostatin propeptide despite an unchanged fiber-type composition. These data and the role of myostatin in the regulation of Peroxisome Proliferator-Activated Receptor (PPAR) transcriptional activators comprehensively illustrate the importance of myostatin as a pivotal factor balancing size and strength of skeletal muscle against endurance through adaptation of its energy metabolism. 


\section{RESULTS}

Decreased endurance exercise capacity and voluntary locomotor activity in myostatin deficiency

An index for endurance exercise capacity is the maximal oxygen uptake per body weight $\left(\mathrm{VO}_{2} \max \left[\mathrm{ml} \mathrm{O}_{2} / \mathrm{min} / \mathrm{kg}\right]\right)$, which was determined by running on a treadmill at incremental speeds in a metabolic cage. Initially, the oxygen uptake is proportional to the running speed but levels off at a plateau, the so-called $\mathrm{VO}_{2} \max$, beyond which no further increase is possible. Nevertheless, running velocity can still increase beyond the speed at $\mathrm{VO}_{2}$ max to reach the maximal velocity (VPeak $[\mathrm{m} / \mathrm{min}]$ ) before exhaustion of the animals. $\mathrm{VO}_{2}$ max of $\mathrm{Mstn}^{-/-}$ mice was reduced by $10 \%(p=0.004$; Figure $1 A)$ and a similar tendency was shown for vPeak in comparison with $\mathrm{Mstn}^{+/+}$mice $(\mathrm{p}=0.13$; Figure $1 \mathrm{~B})$, while heterozygous $\mathrm{Mstn}^{+/-}$mice had an intermediate phenotype. Hence, such decreased oxygen consumption in vivo parallels the decreased oxidative phosphorylation rates in vitro (Figure $2 \mathrm{G}$ ). However, absolute $\mathrm{VO}_{2} \mathrm{max}$ $\left[\mathrm{ml} / \mathrm{min}\right.$ ] of $\mathrm{Msth}^{-/-}$mice was increased by $14 \%(\mathrm{p}=0.004$; Figure $1 \mathrm{C})$ owing to a respective $20 \%$ and $24 \%$ increase of total and lean body mass ( $p<0.01$; data not shown). In consequence, the energy cost of running (running economy at $13 \mathrm{~m} / \mathrm{min}$ ) was increased by $15 \%$ in $\mathrm{Mstn}^{-/-}$as compared to $\mathrm{Mstn}^{+/+}$mice ( $\mathrm{p}=0.01$; Figure 1D).

"Critical Speed" accurately reflects the capacity for aerobic exercise and is based on the proportional relationship between distance run and time to exhaustion at different velocities (8). $\mathrm{Mstn}^{-/-}$mice became exhausted more rapidly, resulting in a $30 \%$ lower Critical Speed as compared with $\mathrm{Mstn}^{+/+}$mice (15.9 \pm 1.2 vs $22.9 \pm 1.2 \mathrm{~m} / \mathrm{min}, \mathrm{p}<0.001$; Figure 1E). These findings provide further evidence that the double muscle phenotype we observed in $\mathrm{Mstn}^{-/-}$mice (16.4 \pm 0.3 vs $8.4 \pm 0.2 \mathrm{mg}$ for soleus muscle, as compared to $\mathrm{Mstn}^{+/+}$mice, $\mathrm{p}<0.001$; similar observations were made for others hind limb muscles) cannot compensate for inefficient energy metabolism to maintain endurance capacity. The "Respiratory Exchange Ratio" (RER),

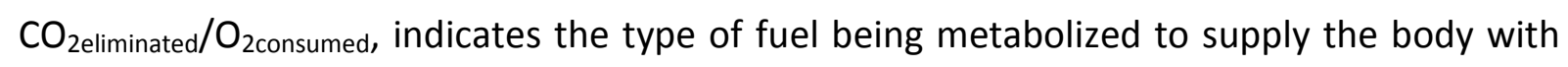
energy. Resting and maximal RER were slightly increased in $\mathrm{Mstn}^{+/-}$mice and even further increased in $\mathrm{Mstn}^{-/-}$mice as compared with wildtype animals (Figure 1F). This implicates a preference for glycolysis over fatty acid oxidation, which is considered to be disadvantageous for endurance exercise (46). 
In order to evaluate the impact of decreased endurance capacity on voluntary locomotion, total night-time activity was measured and revealed no significant difference between Mstn /- and $\mathrm{Mstn}^{+/+}$mice, although we observed a trend towards lower total locomotor activity in myostatin deficiency $(1,792 \pm 279$ counts/12 hours and 2,333 \pm 255 counts/12 hours respectively, $\mathrm{p}=0.16)$. However, upon a metabolic challenge consisting of food deprivation, $\mathrm{Msth}^{-/-}$ mice failed to increase their locomotor activity as compared to the marked increase seen in $\mathrm{Msth}^{+/+}$mice (Figure 1G), which further demonstrates that myostatin deficiency impairs locomotion.

\section{Profound fatigability of myostatin deficient skeletal muscle}

In order to assess the contribution of skeletal muscle fatigability to the decrease of endurance capacity in $\mathrm{Mstn}^{-/-}$mice, we next determined how muscle force was maintained upon repetitive stimulation. Soleus muscle from $\mathrm{Msth}^{-/-}$mice fatigued far more rapidly following repetitive stimulation $\left.\left(\mathrm{t}_{[30 \%} \mathrm{Po}\right]=72 \mathrm{~s}\right)$ as compared to $\mathrm{Mstn}^{+/+}$soleus $\left(\mathrm{t}_{[30 \%} \mathrm{Po}\right]=100 \mathrm{~s}$; $\mathrm{p}<0.001$ ), while heterozygous $\mathrm{Mstn}^{+/-}$muscle had an intermediate phenotype (Figure $2 \mathrm{~A}$ ). Remarkably, myostatin deficient muscle, despite being about twice as strong at the beginning of the experiment $(389 \pm 11$ vs $233 \pm 5 \mathrm{mN}$ for soleus absolute maximal tetanic force P0, as compared to $\mathrm{Mstn}^{+/+}$mice, $\left.\mathrm{p}<0.001\right)$, fatigued so rapidly that absolute maximal force dropped to $\mathrm{Mstn}^{+/+}$levels after $3 \mathrm{~min}$ of repetitive tetanic stimulation (Figure 2B). This rapid force decline caused the specific force of $\mathrm{Mstn}^{-/-}$muscles to decrease from $91 \%$ at the start to $59 \%$ at the end of the fatigue protocol in comparison to Mstn ${ }^{+/+}$muscles $(p=0.04$ and $\mathrm{p}<0.001$ respectively; Figure $2 \mathrm{C}$ ). Interestingly, similar results were found for the fast glycolytic extensor digitorum longus muscle (EDL, -21\% concerning the fatigue index in Mstn ${ }^{-/}$vs $\mathrm{Mstn}^{+/+}$) as well as for the entire posterior lower leg compartment (fatigue index was decreased by $48 \%$ in $\mathrm{Mstn}^{-/-}$vs $\mathrm{Mstn}^{+/+}$), for which measurements were performed in situ to maintain blood perfusion during the stimulation protocol (data not shown).

\section{Increased glycolysis and decreased mitochondrial respiration rates in myostatin deficiency}

To investigate whether increased muscle fatigability in the absence of myostatin resulted from increased anaerobic glucose metabolism-induced muscle acidosis, we determined serum lactate levels after exhaustive treadmill exercise. In Mstn ${ }^{-/-}$mice, serum lactate was already elevated at resting state and increased disproportionately to $12.1 \pm 1.1 \mathrm{mmol} / \mathrm{l}$ at $5 \mathrm{~min}$ post exercise as compared to $5.1 \pm 0.4 \mathrm{mmol} / \mathrm{l}$ in controls $(p<0.001 ;$ Figure $2 \mathrm{D})$. The elevated 
serum lactate in myostatin deficient mice concurred with an increased enzymatic activity of enolase (Figure 2E), a key component of glycolysis. To determine whether lactate accumulation resulted from defective oxidative phosphorylation (OXPHOS), we investigated mitochondrial respiration rates in situ for OXPHOS complexes I, II and IV. Mstn ${ }^{+/+}$muscles revealed higher respiration rates for the predominantly oxidative soleus muscle as compared with the predominantly glycolytic EDL muscle (Figure 2G). Remarkably, the absence of myostatin decreased OXPHOS rates of the soleus muscle to the level of $\mathrm{Mstn}^{+/+}$EDL muscles, and $\mathrm{Mstn}^{--}$EDL further lost OXPHOS activity of up to $42 \%$ (Figure $2 \mathrm{G}$ ). It is unlikely that such OXPHOS reduction was merely due to mitochondrial depletion, because complex I (CXI) activity remained unaltered. The $\mathrm{CxII/CxI}$ and $\mathrm{CxIV/CxI}$ ratios decreased in myostatin deficient muscle, which might be an indicator for qualitative changes in the assembly of the cytochrome c oxidase (complex IV) and of the entirely nuclear encoded succinate dehydrogenase (complex II), (Figure 2F). In fact, the biochemical profile of mitochondria from Mstn ${ }^{-/}$soleus muscle resembled that of $\mathrm{Mstn}^{+/+}$EDL mitochondria and suggested a shift of mitochondrial qualities from the "slow oxidative" to the "fast glycolytic" type. This shift in metabolic activity was accompanied by a profound conversion of the contractile phenotype of $\mathrm{Mstn}^{-/}$soleus muscle away from slow/oxidative myosin heavy chain type 1 (MHC-1) towards fast/glycolytic MHC-2x/MHC-2b (Figures $3 \mathrm{~A}-\mathrm{C}$ ). In line with these observations are the findings that the $\mathrm{K}_{m}(A D P)$ in resting soleus muscle was much higher than that for EDL muscle (Figure $2 \mathrm{H}$ ). $\mathrm{K}_{\mathrm{m}}(\mathrm{ADP})$ was decreased by addition of creatine, in both EDL and soleus muscle demonstrating the coupling between mitochondrial creatine kinase and the adenine nucleotide translocase. Absence of myostatin lowered the $K_{m}(A D P)$ of the soleus muscle towards the level of the fast glycolytic EDL muscle, and the $\mathrm{K}_{\mathrm{m}}(\mathrm{ADP})$ of $\mathrm{Mstn}^{-/-}$EDL decreased even further (Figure $2 \mathrm{H})$.

\section{Decreased expression of PPAR transcription factors in myostatin deficient muscle}

We next aimed to gain insight into the molecular mechanism of the metabolic dysregulation observed in myostatin deficiency. We hypothesized that myostatin might act in a signaling cascade upstream of PPAR transcriptional regulators because inactivation of myostatin as well as of $P$ par $\beta / \delta$ (43) both resulted in a similar loss of the oxidative phenotype. In wildtype mice, as expected, Pparb/d, Ppara and Pparg mRNA expression levels were 2-3 times higher in the predominantly oxidative soleus muscle than in the predominantly glycolytic EDL mus- 
cle. As predicted, PPAR mRNA levels in the soleus muscle of $\mathrm{Mstn}^{-/-}$mice (Figure 3D) fell to about the level seen in $\mathrm{Mstn}^{+/+}$EDL muscle (Figure 3E), while in the EDL muscle of $\mathrm{Mstn}^{-/-}$ mice fell below the already low values found in $\mathrm{Mstn}^{+/+} \mathrm{EDL}$, although this was statistically significant only for Ppara (Figure 3E). Together, these results suggest that myostatin may promote high oxidative metabolism in skeletal muscle via PPAR signaling.

\section{Myostatin blockade by AAV-propeptide in adult mice increases fatigability}

To determine the role of myostatin on energy dependent muscle function during adulthood, we over-expressed myostatin propeptide using AAV as expression vectors. Injection of AAV2/8-propeptide into the femoral artery led to robust transgene expression (Figure 4A) and slight increase of the lower leg muscle weight (Figure 4B). Importantly, soleus muscle fatigued more rapidly after propeptide treatment (Figure 4D), despite only minimal changes of absolute maximal and specific force at the start of the fatigue protocol (Figure 4D) and an unaltered fiber-type composition (Figure 4C). Interestingly, mRNA levels of Pparb/d and Pgc1a transcripts were reduced (Figure 4E), suggesting changes in the regulation of oxidative metabolism independent of muscle fiber-type composition. Moreover, myostatin propeptide treatment diminished exercise capacity six months after systemic intravenous treatment with myostatin AAV2/8-propeptide (Figures 4F and 4G), despite similar body weights (24.1 $\pm 0.7 \mathrm{~g}$ vs $24.4 \pm 0.6 \mathrm{~g}$ for mice treated with PBS vs AAV2/8-propeptide, respectively; $p=0.79$ ). Hence we were able to show that myostatin blockade in adult wildtype mice caused a similar deficit in aerobic muscle properties as shown for $\mathrm{Mstn}^{-/}$mice and that these effects were independent of muscle fiber-type composition. 


\section{DISCUSSION}

Myostatin exerts a dual function on skeletal muscle as it limits its size while promoting oxidative properties. We here show that myostatin acts to economize muscle energy expenditure, because smaller muscle requires less oxygen during exercise. The higher OXPHOS activity and lower respiratory exchange ratio point towards increased fatty acid consumption as a preferred fuel in the presence of myostatin and suggests higher energy efficiency as compared with the energetically less efficient glycolysis in states of myostatin deficiency. The emerging property of myostatin to save fuel combined with a simultaneous increase in running endurance and maximal running velocity might explain the high conservation of myostatin during evolution and the rare occurrence of myostatin mutations. The comparison of muscle physiology between hypermuscular myostatin knockout and wildtype mice sheds light on the fact that myostatin deficient muscle confers little functional advantage over wildtype muscle due to its rapid fatigability. We have demonstrated that the fatigability and diminished capacity for forced and voluntary locomotor activities seen in $\mathrm{Mstn}^{-/}$described by us and others $(18,29,39,42)$ goes in parallel with a reduction of muscle OXPHOS activities. Interestingly, recent in vivo investigations using ${ }^{31} \mathrm{P}$-Magnetic Resonance Spectroscopy (MRS) supports our findings as the relative contribution of oxidative ATP production to total ATP turnover was reduced following repeated isometric contractions of $\mathrm{Msth}^{-/}$muscles, whereas the ATP cost of contraction was increased (15). Thus, muscle strength due to myostatin deficiency comes at the cost of exercise intolerance, which is often seen in patients with mitochondrial disorders such as MELAS or MERRF syndrome (24). Interestingly, muscle cramps are frequently observed in whippet dogs with Mstn mutation (37). Moreover, "double muscle cattle", several breeds of which have been identified to carry Mstn mutations $(17,30)$, are prone to exercise induced lactic acidosis and severe rhabdomyolysis $(20,21)$.

However, a number of questions result from our work. We ask, whether the observed decrease in oxidative metabolism and energy dependent muscle function might be an indirect effect and a consequence of the profound congenital fiber-type change that is typically found in the constitutive absence of myostatin. We thus blocked myostatin in adult wildtype mice using myostatin propeptide, which did not affect fiber-type composition. This is in agreement with previous studies following blockade of myostatin or its activin IIB receptor (ActRIIB) signaling $(3,11,12,36)$. Importantly, treatment with soluble ActRIIB-Fc to block 
myostatin and homologues signaling factors caused an mRNA expression profile away from oxidative metabolism (41). Supporting the hypothesis that myostatin regulates oxidative metabolism independently of muscle fiber composition, we here found that treatment with myostatin propeptide caused muscle fatigability and decreased aerobic exercise capacity.

We show that myostatin deficiency has an influence on the expression of Ppar- $\alpha / \beta / \gamma$ transcription factors, which control metabolic properties but not muscle mass $(43,45)$. This indicates that myostatin may control the muscle oxidative phenotype notably via PPAR activity. Indeed, downstream targets of Ppar- $\beta$ such as Pgc1- $\alpha$ and Cox4 were down-regulated in $\mathrm{Mstn}^{-/-}$mice (26). Furthermore, knockout of Pparb, similar to the findings in $\mathrm{Mstn}^{-/-}$mice, reduced oxidative properties of skeletal muscle (43). Importantly, we here show, that myostatin blockade in adult mice following overexpression of myostatin propeptide also reduced expression of Pparb and Pgc1a, supporting the hypothesis that myostatin directly regulates oxidative metabolism. However, the exact molecular mechanism remains to be elucidated as yet little is known about direct molecular targets of myostatin signaling.

Interestingly, distinct but complementary effects on the metabolic profile of obese insulinresistant mice occur when Ppar- $\beta$ is activated and myostatin inhibited (7). Moreover, work on myostatin-mediated effects through $\operatorname{AMPK}(23,44,48)$ raise a number of questions concerning mediators and signaling pathways implicated on muscular metabolic effects of myostatin. It would be of interest to substantiate these findings by an analysis of the muscle microRNA network as this was recently shown to control metabolism via nuclear receptors such as PPARs (14).

A further question concerns the problem, whether muscle hypertrophy following lack of myostatin changes the oxidative muscle metabolism. In fact, we previously have shown that long-term exercise improved contractile and metabolic features of $\mathrm{Mstn}^{-/-}$mice, however, these improvements were associated with a loss of muscle hypertrophy (28). These results suggest that regulation of muscle size and metabolic phenotype by myostatin are linked. It remains to be determined, however, whether the regulation of both processes can be dissociated from each other.

Can we generalize the conclusion of our work that lack or blockade of myostatin always negatively affects aerobic muscle function? It is important to note that previous work demonstrated a beneficial effect of myostatin blockade during ageing (38). It is quite likely that my- 
ostatin blockade in conditions of muscle atrophy through pathological up-regulation of myostatin (e.g. in sarcopenia, cardiac and tumor cachexia), might outweigh the negative effect on muscle metabolism by far $(19,27,49)$. Similarly, myostatin blockade improved running performance in obese and insulin resistant (ob/ob) mice (7). Again, benefits on insulin signaling and glucose metabolism may largely outweigh potential negative effects on muscle oxidative metabolism, especially if combined with a Ppar- $\beta$ agonist. It should be noted that treatment of adult mice under high fat diet with soluble ActRIIB did not alter fat mass and glucose metabolism (33), whereas treatment of obese and insulin resistant mice (ob/ob) with anti-myostatin antibodies improved glucose homeostasis and glucose tolerance (7). In fact, the metabolic changes following myostatin blockade could be beneficial for patients with insulin resistance, and recently it was shown that AAV-propeptide overexpression mediated higher glucose uptake in skeletal muscle, which is likely mediated by an up-regulation of membrane glucose transporters (12). Thus, further work is required to define under which circumstances myostatin blockade could exert beneficial effects to combat insulin resistance and overweight.

In conclusion, our results suggest that myostatin increases oxidative metabolism of skeletal muscle thereby improving exercise endurance. These fundamental functions of myostatin should be taken into account when developing therapies based on myostatin blockade. Further investigations are required to answer the question whether emerging therapies based on PPAR agonists might be able to prevent adverse effects of myostatin blockade on the oxidative metabolism and exercise tolerance. 


\section{Methods}

\section{Animals}

$\mathrm{Mstn}^{+/+}, \mathrm{Mstn}^{+/-}$and $\mathrm{Mstn}^{-/-}$mice, on a C57BL/6J background (31), were bred using a heterozygous mating system in the animal facility of CERFE (Evry, France) and kept according to institutional guidelines. Investigations on mice (from 2 to 6 months old) were carried out under the laboratory and animal facility licenses A75-13-11 and A91-228-107. Partly, C57BL/6J control mice $\left(\mathrm{Mstn}^{+/+}\right)$were purchased from Charles River (France). Body mass composition (lean tissue mass, fat mass, free water and total water content) was analyzed using an Echo Medical systems' EchoMRI (Whole Body Composition Analyzers, EchoMRI, Houston, USA).

\section{Evaluation of exercise performance}

\section{[A] Evaluation of the Critical Speed}

The Critical Speed (CSp) defines the proportional relationship between distance run and time to exhaustion at different velocities. Mice were exercised on a 10.6 x $30 \mathrm{~cm}$ double-lane treadmill (LE 8709, Bioseb, Chaville, France) as published (8). The protocol consisted of four runs at various speeds (between 20 and $80 \mathrm{~cm} / \mathrm{s}$ according to individual motor capacity, one run per day) leading to exhaustion between 3 and $45 \mathrm{~min}$. CSp is based on the hyperbolic relationship between speed and time to fatigue during separate bouts of exhaustive runs performed at different speeds. Therefore, CSp was calculated from the slope (a) of the regression line, plotting the distance $(y)$ versus the time to exhaustion $(x)$ from the four runs, according to the equation $y=a x+b$ ( $b$ being the anaerobic distance capacity).

\section{[B] Blood lactate assessment during exhaustive exercise}

Lactate concentration was determined in blood samples $(5 \mu \mathrm{l})$ collected from the tip of the tail using a Lactate pro LT device (Arkray Inc., Kyoto, Japan) at the time points 0 and 5 min after treadmill running-induced exhaustion. Exhaustion was defined as the time point at which mice could not run anymore and stayed on the grid despite repeated electric stimulation. The running test started at the lowest speed of $5 \mathrm{~cm} / \mathrm{s}$ to allow a warm-up and was increased by $1 \mathrm{~cm} / \mathrm{s}$ every 30 seconds until exhaustion.

\section{[C] Measurement of maximal oxygen consumption}

An index of endurance exercise capacity is the maximal oxygen uptake per body weight 
( $\left.\mathrm{VO}_{2} \mathrm{max}\right)$. Initially, oxygen uptake is proportional to the running speed, and this relationship peaks at a plateau, the so-called $\mathrm{VO}_{2}$ max. Oxygen consumption was measured by means of a rapid-flow, open-circuit indirect calorimeter fitted with a one-lane motorized treadmill (Columbus Instrument, Columbus, $\mathrm{OH}$ ) as published (25). The single-lane test treadmill was placed in a metabolic chamber. Ambient air was flushed through the chamber at a rate of $0.66 \mathrm{l} / \mathrm{min}$, and gas samples were extracted to measure oxygen content (Oxymax, Columbus instrument, Columbus, $\mathrm{OH}$ ). Gas samples were dried, measured every $15 \mathrm{~s}$ and oxygen consumption $\left(\mathrm{VO}_{2}\right)$ was calculated using Oxymax software. The gas analyzers were calibrated with standardized gas mixtures before every test session (Air Products, Paris, France), as recommended by the manufacturer. The test described below provided a measure of $\mathrm{VO}_{2} \max$, defined as the highest oxygen consumption attained during the testing protocol. The velocity attained by the mouse at this $\mathrm{VO}_{2}$ max was then considered as the $\mathrm{VVO}_{2}$ max. The maximal velocity (vPeak) was measured at the end of the test.

\section{[D] Incremental test load}

Mice were treadmill exercised on with adjustable belt speed $(0-99.9 \mathrm{~m} / \mathrm{min})$ and electric shock bars (0-2 mA) at the rear of the belt to provide a stimulus encouraging each mouse to run. Over a one week period, the mice were familiarized with the treadmill through the completion of four $10 \mathrm{~min}$ running sessions from 0 to $9 \mathrm{~m} / \mathrm{min}$. The mice subsequently performed an incremental exercise test, without slope. The exercise intensity was increased by $3 \mathrm{~m} / \mathrm{min}$ (starting from $10 \mathrm{~m} / \mathrm{min}$ ) every $3 \mathrm{~min}$, and the exercise continued until exhaustion.

\section{Measurement of voluntary locomotion}

Total voluntary locomotor activities were determined in individual cages with bedding, food and water (Labmaster, TSE Systems $\mathrm{GmbH}$ ). Animals were acclimated in individual cages for 48 hours before experimental measurements. Each cage was embedded in a frame with an infrared light beam-based activity monitoring system, allowing measurement of total locomotor activity. Data were collected in intervals of 40 minutes during the whole experiment and the activity level was recorded as the number of beam interruptions per $40 \mathrm{~min}$. Mice had access to food and water ad libitum except for the 24 hours fasting in order to stimulate locomotor activity of mice.

\section{Measurement of contractile properties}


The contractile properties of extensor digitorum longus (EDL) and soleus muscles were studied in vitro according to previously published protocols (2). Muscles were soaked in an oxygenated Tyrode solution $\left(95 \% \mathrm{O}_{2}\right.$ and $5 \% \mathrm{CO}_{2}$ ) containing $58.5 \mathrm{mM} \mathrm{NaCl}, 24 \mathrm{mM} \mathrm{NaHCO} 3,5.4$ $\mathrm{mM} \mathrm{KCl}, 1.2 \mathrm{mM} \mathrm{KH}_{2} \mathrm{PO}_{4}, 1.8 \mathrm{mM} \mathrm{CaCl}_{2}, 1 \mathrm{mM} \mathrm{MgSO}_{4}$ and $10 \mathrm{mM}$ glucose (pH7.4) and maintained at a temperature of $22^{\circ} \mathrm{C}$. One muscle tendon was attached to a lever arm of a servomotor system (300B, Dual-Mode Lever, Aurora). After equilibration (30 min), field electrical stimulation was delivered through electrodes running parallel to the muscle. Pulses of 1 ms were generated by a high power stimulator (701B, Aurora). Absolute maximal isometric tetanic force (P0) was measured during tetanic contractions (frequency of $50-100 \mathrm{~Hz}$, train of stimulation of $1,500 \mathrm{~ms}$ for soleus and $750 \mathrm{~ms}$ for $E D L)$. The muscle length was adjusted to an optimum (LO) that produced PO. Specific maximal isometric force (SPO) was calculated by dividing the force by the estimated cross-sectional area (CSA) of the muscle. Assuming muscles have a cylindrical shape and a density of $1.06 \mathrm{mg} / \mathrm{mm}^{3}$, the CSA corresponds to the volume of the muscle divided by its fiber length (Lf). The Lf to LO ratio of 0.70 (soleus) or 0.45 (EDL) was used to calculate Lf. Maximal power (Pmax) was determined from force-velocity data that were obtained by eliciting contractions (train of $1,000 \mathrm{~ms}, 150 \mathrm{~Hz}$ ) at 3-5 different afterloads (10-40\% P0). Specific Pmax (sPmax) was calculated by dividing Pmax by muscle weight. Fatigue resistance was then determined after a 5 min rest period. The muscles were stimulated at $75 \mathrm{~Hz}$ during $500 \mathrm{~ms}$, every two second, for $3 \mathrm{~min}$. The time taken for initial force to fall by $50 \%$ (EDL) or $30 \%$ (soleus) was then measured. All data were recorded and analyzed on a microcomputer, using the PowerLab system (4SP, AD Instruments) and software (Chart 4, ADInstruments).

The isometric contractile properties of gastrocnemius (+soleus) were studied in situ as previously described (22). Mice were anesthetized (pentobarbitone sodium, $50 \mathrm{mg} / \mathrm{kg}$ ). Supplemental doses were given as required to maintain deep anesthesia throughout the experiments. The foot was fixed with clamp and the knee was immobilized using stainless steel pins. The distal tendon of the plantaris muscle was cut. The Achilles tendon was attached to an isometric force transducer (Harvard). Great care was taken to ensure that the blood and nerve supply remained intact during surgery. The sciatic nerves were severed proximally and stimulated distally by a bipolar silver electrode using supra-maximal square wave pulses of $0.1 \mathrm{~ms}$ duration. All isometric measurements were made at an initial muscle length of L0. 
Force productions in response to tetanic stimulations (P0) were successively recorded (pulse frequency from 50 to $150 \mathrm{~Hz}$, train duration of $500 \mathrm{~ms}$ ), at least 1 min was allowed between each contractions. The muscle mass $(\mathrm{m})$ was measured to calculate sP0. Fatigue resistance was then determined after a 5 min rest period. The muscle was stimulated during $500 \mathrm{~ms}$ at $100 \mathrm{~Hz}$, every $2 \mathrm{~s}$, for $3 \mathrm{~min}$. The duration corresponding to a force decreased by $50 \%$ was noted. After contractile measurements, the animals were killed with an overdose of pentobarbitone. Muscles were then weighed, frozen in liquid nitrogen or in isopentane pre-cooled in liquid nitrogen and stored at $-80^{\circ} \mathrm{C}$ until histology or biochemical analyses.

\section{Mitochondrial respiration and cytosolic enzyme measurements}

\section{[A] Measurement of OXPHOS activity}

The mitochondrial respiration was studied in vitro in saponin-skinned fibers. Briefly, fibers were separated under a binocular microscope in solution $S$ at $4^{\circ} \mathrm{C}$ (see below) and permeabilized in solution $S$ with $50 \mu \mathrm{g} / \mathrm{ml}$ of saponin for $30 \mathrm{~min}$. After being placed $10 \mathrm{~min}$ in solution $R$ (see below) to wash out adenine nucleotides and creatine phosphate, skinned separated fibers were transferred into a $3 \mathrm{ml}$ water-jacketed oxygraphic cell (Strathkelvin Instruments, Glasgow, UK) equipped with a Clark electrode, as previously described (5), under continuous stirring. Solutions $R$ and $S$ contained the following: $2.77 \mathrm{mM} \mathrm{CaK}_{2} \mathrm{EGTA} 7.23 \mathrm{mM}$ $\mathrm{K}_{2}$ EGTA (100 nM free $\mathrm{Ca}^{2+}$ ), $1 \mathrm{mM}$ free $\mathrm{Mg}^{2+}, 20 \mathrm{mM}$ taurine, $0.5 \mathrm{mM}$ DTT, $50 \mathrm{mM}$ potassium-methane sulfonate (160 mM ionic strength), and $20 \mathrm{mM}$ imidazole (pH 7.1). Solution $S$ also contained $5.7 \mathrm{mM} \mathrm{Na}$ ATP, $15 \mathrm{mM}$ creatine-phosphate, while solution $R$ contained 5 $\mathrm{mM}$ glutamate, $2 \mathrm{mM}$ malate, $3 \mathrm{mM}$ phosphate, and $2 \mathrm{mg} / \mathrm{ml}$ FA free bovine serum. After the experiments, fibers were harvested and dried, and respiration rates were expressed as micromoles of $\mathrm{O}_{2}$ per minute per gram dry weight. Solution $R^{-}$was similar to solution $R$ without substrates and was used to determined maximal $\mathrm{VO}_{2}$ rates for different substrates

\section{[B] Measurement of the maximal muscular oxidative capacities}

After the determination of the basal respiration rate $V_{0}$, the maximal fiber respiration rate was measured at $22^{\circ} \mathrm{C}$ in the presence of a saturating $(2 \mathrm{mM})$ ADP concentration as phosphate acceptor and glutamate-malate as mitochondrial substrates $\left(\mathrm{V}_{\mathrm{GM}}\right)$. The acceptor control ratio was $\mathrm{V}_{\mathrm{GM}} / \mathrm{V}_{0}$ and represented the degree of coupling between oxidation and phosphorylation.

\section{[C] Measurement of the respiratory chain complexes}


When $V_{G M}$ was recorded, electron flow goes through complexes I, II, III, and IV. Then 4 min after this $V_{G M}$ measurement, the complex I was blocked with amytal $(2 \mathrm{mM})$, and then complex II was stimulated with succinate $(25 \mathrm{mM})$. In these conditions, mitochondrial respiration was effected by complexes II, III, and IV $\left(\mathrm{V}_{S}\right)$. After that, $N, N, N^{\prime}, N^{\prime}$-tetramethyl-pphenylenediamine dihydrochloride (TMPD, $0.5 \mathrm{mM})$ and ascorbate $(0.5 \mathrm{mM})$ were added as an artificial electron donor to cytochrome $C$. In these conditions, cytochrome $C$ oxidase (complex IV) was studied as an isolated step of respiratory chain $\left(\mathrm{V}_{\mathrm{TMPD}}\right)$. The ratios $\mathrm{V}_{\mathrm{S}} / \mathrm{V}_{\mathrm{GM}}$ and $\mathrm{V}_{\mathrm{TMPD}} / \mathrm{V}_{\mathrm{GM}}$ allow exploration of complexes I, II, and IV.

\section{[D] Measurement of enolase activity}

Enolase activity was determined in extracts from frozen cryostat sections using a coupled enzyme assay (35).

\section{Immunostaining and SDS-PAGE}

For MHC-immunohistochemistry, primary antibodies were: MHC-1 (hybridoma\#BA-D5, Deutsche Sammlung von Mikroorganismen und Zellkulturen DSMZ), MHC-2a (hybridoma\#SC-71, DSMZ), MHC-2x (hybridoma\#6H1, Developmental Studies Hybridoma Bank) and MHC-2b (hybridoma\#BF-F3, DSMZ). Briefly, frozen unfixed $10 \mu \mathrm{m}$ sections were blocked $1 \mathrm{~h}$ in PBS plus 1\% BSA, 1\% sheep serum, $0.01 \%$ Triton $\mathrm{X}-100$ and $0.001 \%$ sodium azide. Sections were then incubated overnight with primary antibodies against laminin (Dako) and MHC isoforms. After washes in PBS, sections were incubated $1 \mathrm{~h}$ with secondary antibodies. Slides were finally mounted in Fluoromont (Southern Biotech). Morphometric analyses were made on whole soleus muscles. Images were captured using a digital camera (Hamamatsu ORCAAG) attached to a motorized fluorescence microscope (Zeiss Axiolmager.Z1), and morphometric analyses were made using the software MetaMorph 7.5 (Molecular Devices).

For MHC gel electrophoresis, the muscles were extracted on ice for 60 minutes in 4 volumes of extracting buffer ( $\mathrm{pH} \mathrm{6.5)}$ ) as previously described (10). Following centrifugation, the supernatants were diluted 1:1 (v/v) with glycerol and stored at $-20^{\circ} \mathrm{C}$. MHC isoforms (MHC-1, MHC-2a, MHC-2x, MHC-2b) were separated on $8 \%$ polyacrylamide gels which were made in the Bio-Rad mini-Protean II Dual slab cell system as described previously (1). The gels were run for 31 hours at a constant voltage of $72 \mathrm{~V}$ at $4^{\circ} \mathrm{C}$. Following migration, the gels were silver stained. The positions of the different MHC bands were confirmed by Western blotting 
using antibodies directed against different MHC isoforms. The gels were scanned using a video acquisition system.

\section{Production and injection of AAV-propeptide for adult myostatin blockade}

The myostatin propeptide construct, prepared by PCR amplification of C57BL/6J CDNA, using the primers 5'-CCG CTC GAG ATG ATG CAA AAA CTG CAA ATG-3' and 5'-CCG GGA TCC CTA TTA GTC TCT CCG GGA CCT CTT-3', was introduced into an AAV-2-based vector between the 2 inverted terminal repeats and under the control of the cytomegaly virus promoter using the $\mathrm{Xhol}$ and $\mathrm{BamHI}$ sites. The AAV myostatin propeptide was produced in human embryonic kidney 293 cells by the triple-transfection method using the calcium phosphate precipitation technique with both the pAAV2 propeptide plasmid, the pXX6 plasmid coding for the adenoviral sequences essential for AAV production, and the pRepCAp plasmid coding for AAV8 capsid. The virus was then purified by 2 cycles of cesium chloride gradient centrifugation and concentrated by dialysis. The final viral preparations were kept in PBS solution at $-80^{\circ} \mathrm{C}$. The particle titer (number of viral genomes) was determined by a quantitative PCR.

The detailed procedure for intra-arterial injection was previously described (16). Briefly, anesthetized 2-month-old C57BL/6J wildtype male mice underwent femoral artery and vein isolation of the right hind limb. After clamping the femoral vein and two collaterals, a catheter was introduced into the femoral artery and the AAV preparation $\left(2.5 \times 10^{12} \mathrm{vg}\right.$ per injection) was injected in a volume of $1 \mathrm{ml}$ per $20 \mathrm{~g}$ of body weight at a rate of $100 \mu \mathrm{l} / \mathrm{s}$. Thereafter, the left hind limb was processed in the same manner and injected with a same volume of PBS. For systemic delivery, $1 \times 10^{13} \mathrm{vg}$ of AAV2/8-myostatin propeptide was injected into the retro-orbital sinus or with PBS for controls.

\section{RT-qPCR}

Total RNA was extracted from frozen muscle after pulverization in liquid nitrogen and from cultured $\mathrm{C}_{2} \mathrm{C}_{12}$ cell pellets with the TRIzol ${ }^{\circledR}$ (Invitrogen) extraction protocol. $2.25 \mu \mathrm{g}$ total RNA were reversely transcribed using the Thermoscript ${ }^{\circledR}$ RT-PCR System (Invitrogen) with random hexamers in $60 \mu \mathrm{l}$ reaction volume of which we used $4 \mu \mathrm{l}$ for each subsequent qPCR-reaction and $2 \mu \mathrm{l}$ of a 1:10 dilution for the $18 \mathrm{~S}$ reference gene. We used the following oligonucleotide primers for qPCR: 185 rRNA (reference gene): (F) 5'-CAT TCG AAC GTC TGC CCT ATC-3', (R) 5'CTC CCT CTC CGG AAT CGA AC-3'; Ppara: (F) 5'-GGG CAA GAG AAT CCA CGA AG-3', (R) 5'-CGT 
CTT CTC GGC CAT ACA CA-3'; Pparb/d: (F) 5'-AGC CAC AAC GCA CCC TTT-3', (R) 5'-CGG TAG AAC ACG TGC ACA CT-3'; Pparg: (F) 5'-CGA GTC TGT GGG GAT AAA GC-3', (R) 5'-GGA TCC GGC AGT TAA GAT CA-3'; Pgc1a: (F) 5'-GAA AGG GCC AAA CAG AGA GA-3', (R) 5'-GTA AAT CAC ACG GCG CTC TT-3'. The qPCR for each sample was run with the SYBR Green ${ }^{\circledR}$ protocol (Applied Biosystems) in triplicate on an ABI PRISM 7700 sequence detection system (Applied Biosystems) with a hotstart Taq polymerase. A 10 min denaturation step at $94^{\circ} \mathrm{C}$ was followed by 45 cycles of denaturation at $94^{\circ} \mathrm{C}$ for $10 \mathrm{~s}$ and annealing/extension at $60^{\circ} \mathrm{C}$ for $30 \mathrm{~s}$. Before sample analysis we had determined for each gene the PCR efficiencies with a standard dilution series $\left(10^{0}-10^{7}\right.$ copies/ $\left.\mu l\right)$, which subsequently enabled us to calculate the copy numbers from the $C_{t}$ values, using the $-\Delta \Delta C_{t}$ method.

\section{Statistical analysis}

Data were analyzed using either one-way ANOVA, followed by Tukey post-hoc test, or paired/unpaired Student's $t$ tests. Values are presented as means \pm SEM. The significance level was set at $p<0.05$. 


\section{ACKNOWLEDGEMENTS}

We would like to acknowledge Stéphanie Rimbaud for helping with the mitochondrial respiration protocol and the Functional \& Physiological Exploration Platform (FPE, Université Paris Diderot, Sorbonne, Paris Cité, BFA, EAC 4413 CNRS, F-75205 Paris, France).

\section{GRANTS}

This work was supported by the Association Française contre les Myopathies towards HA, AF, AV, LG, and EM, Association Monegasque contre les Myopathies and the Parents Project France towards $\mathrm{HA}$ and $\mathrm{CH}$, Aktion Benni \& Co towards HA, the Deutsche Forschungsgemeinschaft and the Université Franco-Allemand towards KR, HA and MS (as part of the MyoGrad International Graduate School for Myology DRK 1631/1 and CDFA-06-11), and NeuroCure Exc 257 to MS.

\section{DISCLOSURE}

No conflicts of interest, financial or otherwise, are declared by the authors.

\section{AUTHORS' CONTRIBUTIONS}

$\mathrm{EM}, \mathrm{KR}, \mathrm{LMH}, \mathrm{RD}, \mathrm{CH}, \mathrm{OA}, \mathrm{LA}, \mathrm{SMG}, \mathrm{AV}, \mathrm{AF}$ and $\mathrm{HA}$ carried out the experiments. VB assisted in the measurement of maximal oxygen uptake during exercise. SL assisted in the voluntary locomotor activity experiments. RVC assisted in the mitochondrial respiration experiments. EM, MS and HA carried out all the analyses and the figures. HA designed the study and drafted the manuscript with the help of EM, KP, LG and MS. All authors read and approved of the final manuscript for publication. 


\section{LITERATURE}

1. Agbulut $\mathbf{O}$, Noirez P, Beaumont F, and Butler-Browne G. Myosin heavy chain isoforms in postnatal muscle development of mice. Biol Cell 95: 399-406, 2003.

2. Agbulut O, Vignaud A, Hourde C, Mouisel E, Fougerousse F, Butler-Browne GS, and Ferry A. Slow myosin heavy chain expression in the absence of muscle activity. Am J Physiol Cell Physiol 296: C205-214, 2009.

3. Akpan I, Goncalves MD, Dhir R, Yin X, Pistilli EE, Bogdanovich S, Khurana TS, Ucran J, Lachey J, and Ahima RS. The effects of a soluble activin type IIB receptor on obesity and insulin sensitivity. Int J Obes 33: 1265-1273, 2009.

4. Amthor H, Macharia R, Navarrete R, Schuelke M, Brown SC, Otto A, Voit T, Muntoni F, Vrbova G, Partridge T, Zammit P, Bunger L, and Patel K. Lack of myostatin results in excessive muscle growth but impaired force generation. Proc Natl Acad Sci U S A 104: 18351840, 2007.

5. Athea Y, Viollet B, Mateo P, Rousseau D, Novotova M, Garnier A, Vaulont S, Wilding JR, Grynberg A, Veksler V, Hoerter J, and Ventura-Clapier R. AMP-activated protein kinase alpha2 deficiency affects cardiac cardiolipin homeostasis and mitochondrial function. Diabetes 56: 786-794, 2007.

6. Baligand C, Gilson H, Menard JC, Schakman O, Wary C, Thissen JP, and Carlier PG. Functional assessment of skeletal muscle in intact mice lacking myostatin by concurrent NMR imaging and spectroscopy. Gene Ther 17: 328-337, 2010.

7. Bernardo BL, Wachtmann TS, Cosgrove PG, Kuhn M, Opsahl AC, Judkins KM, Freeman TB, Hadcock JR, and LeBrasseur NK. Postnatal PPARdelta activation and myostatin inhibition exert distinct yet complimentary effects on the metabolic profile of obese insulinresistant mice. PLoS One 5: e11307, 2010.

8. Billat VL, Mouisel E, Roblot N, and Melki J. Inter- and intrastrain variation in mouse critical running speed. J Appl Physiol 98: 1258-1263, 2005.

9. Brown ML, Bonomi L, Ungerleider N, Zina J, Kimura F, Mukherjee A, Sidis Y, and Schneyer A. Follistatin and follistatin like-3 differentially regulate adiposity and glucose homeostasis. Obesity 19: 1940-1949, 2011. 
10. Butler-Browne GS, and Whalen RG. Myosin isozyme transitions occurring during the postnatal development of the rat soleus muscle. Dev Biol 102: 324-334, 1984.

11. Cadena SM, Tomkinson KN, Monnell TE, Spaits MS, Kumar R, Underwood KW, Pearsall RS, and Lachey JL. Administration of a soluble activin type IIB receptor promotes skeletal muscle growth independent of fiber type. J Appl Physiol 109: 635-642, 2010.

12. Cleasby ME, Jarmin S, Eilers W, Elashry M, Andersen DK, Dickson G, and Foster K. Local Overexpression of the Myostatin Propeptide Increases Glucose Transporter Expression and Enhances Skeletal Muscle Glucose Disposal. Am J Physiol Endocrinol Metab, 2014.

13. Fournier B, Murray B, Gutzwiller S, Marcaletti S, Marcellin D, Bergling S, Brachat S, Persohn E, Pierrel E, Bombard F, Hatakeyama S, Trendelenburg AU, Morvan F, Richardson B, Glass DJ, Lach-Trifilieff E, and Feige JN. Blockade of the activin receptor IIb activates functional brown adipogenesis and thermogenesis by inducing mitochondrial oxidative metabolism. Mol Cell Biol 32: 2871-2879, 2012.

14. Gan Z, Rumsey J, Hazen BC, Lai L, Leone TC, Vega RB, Xie H, Conley KE, Auwerx J, Smith SR, Olson EN, Kralli A, and Kelly DP. Nuclear receptor/microRNA circuitry links muscle fiber type to energy metabolism. J Clin Invest 123: 2564-2575, 2013.

15. Giannesini B, Vilmen C, Amthor H, Bernard M, and Bendahan D. Lack of myostatin impairs mechanical performance and ATP cost of contraction in exercising mouse gastrocnemius muscle in vivo. Am J Physiol Endocrinol Metab 305: E33-40, 2013.

16. Gonin P, Arandel A, Van Wittenberghe L, Marais T, Perez N, and Danos O. Femoralintra-arterial injection: a tool to deliver and assess recombinant AAV constructs in rodents whole hind limb. J Gene Med 7: 782-791, 2005.

17. Grobet L, Martin L, Poncelet D, Pirottin D, Brouwers B, Riquet J, Schoeberlein A, Dunner S, Menissier F, Massabanda J, Fries R, Hanset R, and Georges M. A deletion in the bovine myostatin gene causes the double-muscled phenotype in cattle. Nat Genet 17: 71-74, 1997.

18. Hennebry A, Berry C, Siriett V, O'Callaghan P, Chau L, Watson T, Sharma M, and Kambadur R. Myostatin regulates fiber-type composition of skeletal muscle by regulating MEF2 and MyoD gene expression. Am J Physiol Cell Physiol 296: C525-534, 2009. 
19. Heineke J, Auger-Messier M, Xu J, Sargent M, York A, Welle S, and Molkentin JD. Genetic deletion of myostatin from the heart prevents skeletal muscle atrophy in heart failure. Circulation 121: 419-425, 2010.

20. Holmes JH, Ashmore CR, and Robinson DW. Effects of stress on cattle with hereditary muscular hypertrophy. J Anim Sci 36: 684-694, 1973.

21. Holmes JH, Robinson DW, and Ashmore CR. Blood lactic acid and behaviour in cattle with hereditary muscular hypertrophy. J Anim Sci 35: 1011-1013, 1972.

22. Hourde C, Vignaud A, Beurdy I, Martelly I, Keller A, and Ferry A. Sustained peripheral arterial insufficiency durably impairs normal and regenerating skeletal muscle function. J Physiol Sci 56: 361-367, 2006.

23. Hulmi JJ, Oliveira BM, Silvennoinen M, Hoogaars WM, Ma H, Pierre P, Pasternack A, Kainulainen $\mathbf{H}$, and Ritvos $\mathbf{O}$. Muscle protein synthesis, mTORC1/MAPK/Hippo signaling, and capillary density are altered by blocking of myostatin and activins. Am J Physiol Endocrinol Metab 304: E41-50, 2013.

24. Janssen AJ, Schuelke M, Smeitink JA, Trijbels FJ, Sengers RC, Lucke B, Wintjes LT, Morava E, van Engelen BG, Smits BW, Hol FA, Siers MH, Ter Laak H, van der Knaap MS, Van Spronsen FJ, Rodenburg RJ, and van den Heuvel LP. Muscle 3243A-->G mutation load and capacity of the mitochondrial energy-generating system. Ann Neurol 63: 473-481, 2008.

25. Kemi OJ, Loennechen JP, Wisloff $\mathbf{U}$, and Ellingsen $\mathbf{O}$. Intensity-controlled treadmill running in mice: cardiac and skeletal muscle hypertrophy. J Appl Physiol 93: 1301-1309, 2002.

26. Lipina C, Kendall H, McPherron AC, Taylor PM, and Hundal HS. Mechanisms involved in the enhancement of mammalian target of rapamycin signalling and hypertrophy in skeletal muscle of myostatin-deficient mice. FEBS Lett 584: 2403-2408, 2010.

27. Macdonald EM, Andres-Mateos E, Mejias R, Simmers JL, Mi R, Park JS, Ying S, Hoke A, Lee SJ, and Cohn RD. Denervation atrophy is independent from Akt and mTOR activation and is not rescued by myostatin inhibition. Dis Model Mech 2014.

28. Matsakas A, Macharia R, Otto A, Elashry MI, Mouisel E, Romanello V, Sartori R, Amthor H, Sandri M, Narkar V, and Patel K. Exercise training attenuates the hypermuscular 
phenotype and restores skeletal muscle function in the myostatin null mouse. Exp Physiol 97: 125-140, 2012.

29. Matsakas A, Mouisel E, Amthor H, and Patel K. Myostatin knockout mice increase oxidative muscle phenotype as an adaptive response to exercise. J Muscle Res Cell Motil 31: 111-125, 2010.

30. McPherron AC, and Lee SJ. Double muscling in cattle due to mutations in the myostatin gene. Proc Natl Acad Sci U S A 94: 12457-12461, 1997.

31. McPherron AC, Lawler AM, and Lee SJ. Regulation of skeletal muscle mass in mice by a new TGF-beta superfamily member. Nature 387: 83-90, 1997.

32. McPherron AC. Metabolic functions of myostatin and GDF11. Immunol Endocr Metab Agents Med Chem 10: 217-231, 2010.

33. McPherron AC, Guo T, Wang $\mathbf{Q}$, and Portas J. Soluble activin receptor type IIB treatment does not cause fat loss in mice with diet-induced obesity. Diabetes Obes Metab 14: 279-282, 2012.

34. Mendias CL, Marcin JE, Calerdon DR, and Faulkner JA. Contractile properties of EDL and soleus muscles of myostatin-deficient mice. J Appl Physiol 101: 898-905, 2006.

35. Merkulova T, Dehaupas M, Nevers MC, Creminon C, Alameddine H, and Keller A. Differential modulation of alpha, beta and gamma enolase isoforms in regenerating mouse skeletal muscle. Eur J Biochem 267: 3735-3743, 2000.

36. Morine KJ, Bish LT, Selsby JT, Gazzara JA, Pendrak K, Sleeper MM, Barton ER, Lee SJ, and Sweeney HL. Activin IIB receptor blockade attenuates dystrophic pathology in a mouse model of Duchenne muscular dystrophy. Muscle Nerve 42: 722-730, 2010.

37. Mosher DS, Quignon P, Bustamante CD, Sutter NB, Mellersh CS, Parker HG, and Ostrander EA. A mutation in the myostatin gene increases muscle mass and enhances racing performance in heterozygote dogs. PLoS Genet 3: e79, 2007.

38. Murphy KT, Koopman R, Naim T, Léger B, Trieu J, Ibebunjo C, and Lynch GS. Antibody-directed myostatin inhibition in 21-mo-old mice reveals novel roles for myostatin signaling in skeletal muscle structure and function. FASEB J 24: 4433-4442, 2010. 
39. Ploquin C, Chabi B, Fouret G, Vernus B, Feillet-Coudray C, Coudray C, Bonnieu A, and Ramonatxo C. Lack of myostatin alters intermyofibrillar mitochondria activity, unbalances redox status, and impairs tolerance to chronic repetitive contractions in muscle. Am J Physiol Endocrinol Metab 302: E1000-1008, 2012.

40. Qaisar R, Renaud G, Morine K, Barton ER, Sweeney HL, and Larsson L. Is functional hypertrophy and specific force coupled with the addition of myonuclei at the single muscle fiber level? Faseb J 26: 1077-1085, 2012.

41. Rahimov F, King OD, Warsing LC, Powell RE, Emerson CP Jr, Kunkel LM, and Wagner KR. Gene expression profiling of skeletal muscles treated with a soluble activin type IIB receptor. Physiol Genomics 43: 398-407, 2011.

42. Savage $\mathrm{KJ}$, and McPherron AC. Endurance exercise training in myostatin null mice. Muscle Nerve 42: 355-362, 2010.

43. Schuler M, Ali F, Chambon C, Duteil D, Bornert JM, Tardivel A, Desvergne B, Wahli W, Chambon P, and Metzger D. PGC1alpha expression is controlled in skeletal muscles by PPARbeta, whose ablation results in fiber-type switching, obesity, and type 2 diabetes. Cell Metab 4: 407-414, 2006.

44. Shan $\mathbf{T}$, Liang $\mathbf{X}, \mathbf{B i} \mathbf{P}$, and Kuang $\mathbf{S}$. Myostatin knockout drives browning of white adipose tissue through activating the AMPK-PGC1 $\alpha$-Fndc5 pathway in muscle. FASEB J 27: 1981-1989, 2013.

45. Wagner KD, and Wagner N. Peroxisome proliferator-activated receptor beta/delta (PPARbeta/delta) acts as regulator of metabolism linked to multiple cellular functions. Pharmacol Ther 125: 423-435, 2010.

46. Weber JM. Metabolic fuels: regulating fluxes to select mix. J Exp Biol 214: 286-294, 2011.

47. Yadav H, Quijano C, Kamaraju AK, Gavrilova O, Malek R, Chen W, Zerfas P, Zhigang D, Wright EC, Stuelten C, Sun P, Lonning S, Skarulis M, Sumner AE, Finkel T, and Rane SG. Protection from obesity and diabetes by blockade of TGF- $\beta /$ Smad3 signaling. Cell Metab 14: 67-79, 2011. 
48. Zhang C, McFarlane C, Lokireddy S, Bonala S, Ge X, Masuda S, Gluckman PD, Sharma M, and Kambadur R. Myostatin-deficient mice exhibit reduced insulin resistance through activating the AMP-activated protein kinase signalling pathway. Diabetologia 54: 1491-1501, 2011.

49. Zhou X, Wang JL, Lu J, Song Y, Kwak KS, Jiao Q, Rosenfeld R, Chen Q, Boone T, Simonet WS, Lacey DL, Goldberg AL, and Han HQ. Reversal of cancer cachexia and muscle wasting by ActRIIB antagonism leads to prolonged survival. Cell 142: 531-543, 2010. 


\section{FIGURE LEGENDS}

Figure 1: Global motor activity and energy expenditure of adult $\mathrm{Mstn}^{-/-}, \mathrm{Mstn}^{+/-}$, and Mstn $^{+/+}$mice. (A) Maximal oxygen uptake $\left(\mathrm{VO}_{2} \mathrm{max}\right)$ normalized to body weight. (B) Peak running velocity reached after sequential increase of treadmill speed (vPeak). (C) Whole body absolute maximal oxygen consumption. (D) Energetic cost of running measured as oxygen consumption per distance run at $13 \mathrm{~m} / \mathrm{min}$ running speed. (E) The plot depicts the proportional relationship between distance run ( $y$-axis) and time to exhaustion ( $x$-axis) at different velocities. The regression lines together with regression equations indicate the critical speed. (F) Respiratory Exchange Ratio (RER) at rest and at vPeak. (G) Effects of $24 \mathrm{~h}$ food restriction (dashed line) or free feeding (plain line) on total activity (beam interruptions/40 $\min )$. Values are shown as means \pm SEM. Number $(n)$ of mice examined: $n=6 \mathrm{Mstn}^{+/} ; n>8$ $\mathrm{Mstn}^{-/-}$and $\mathrm{Mstn}^{+/+}$.

Figure 2: Effect of myostatin deficiency on muscle force and metabolic properties. (A-C) Studies of muscle fatigue and force in the soleus muscles from 4-months-old female $\mathrm{Mstn}^{+/+}, \mathrm{Mstn}^{+/-}$and $\mathrm{Mstn}^{-/-}$mice. (A) Fatigue index of the soleus muscles given as the time [s] during which the force had declined by $30 \%\left(\mathrm{~T}_{[30 \% \mathrm{PO}]}\right)$. (B) Force recordings during the fatigue protocol over $180 \mathrm{~s}$. (C) Specific force at the beginning and the end of the fatigue protocol. (D-H) Metabolic measurements before and after exercise. (D) Serum lactate levels at rest and $5 \mathrm{~min}$ after exhaustive running exercise. (E) Enolase enzymatic activity of the soleus muscle. (F) Ratios of respiration rates of mitochondrial complexes of soleus and EDL muscles. (G) Mitochondrial respiration rates for complexes I, II and IV of soleus and EDL muscles. (H) Km for ADP and ADP+creatine of soleus and EDL muscles. Values are shown as means \pm SEM. Number $(n)$ of muscles analyzed: $n \geq 6$ for each genotype.

Figure 3: Effect of myostatin deficiency on myofiber-type composition (A-C) and expression of PPAR transcription factors (D-E). (A) Images of fiber-type composition of soleus muscle from $\mathrm{Mstn}^{-/-}$mice and $\mathrm{Mstn}^{+/+}$mice. Immunohistochemistry was performed to depict MHC-1 fibers (green), MHC-2a fibers (purple), MHC-1/2a hybrid fibers (orange), non-stained MHC2x or $\mathrm{MHC} 2 \mathrm{~b}$ fibers (black) and laminin (blue). (B) Relative fiber-type distribution from entire 
transverse sections of the soleus muscle following immunostaining described above. (C) SDSPAGE electrophoresis of MHC isoforms shows an additional band of MHC- $2 b$ expression in Mstn $^{-/-}$mice. (D-E) Relative Ppara, Pparb/d and Pparg mRNA copy numbers in the soleus muscle (D) and EDL muscle (E) from $\mathrm{Mstn}^{+/+}$mice and $\mathrm{Mstn}^{-/-}$mice as expressed per $10^{6} 18 \mathrm{~S}$ rRNA copies. Values are shown as means \pm SEM. Number $(n)$ of muscles analyzed: $n \geq 5$ for each genotype.

Figure 4: Muscular and systemic effects of AAV-propeptide-mediated adult myostatin blockade. (A-E) Functional, morphometric and metabolic analysis of the hind limb muscles one month after injection of AAV2/8-myostatin-propeptide or PBS into femoral arteries of 2-months-old C57BL/6J mice. (A) RT-PCR depicting exogenous myostatin-propeptide expression only after AAV2/8 transfection (lane 1: molecular weight marker; lanes 2-6: individual muscles). (B) Wet weights for soleus, extensor digitorum longus (EDL), plantaris and tibialis anterior (TA) muscles. (C) Soleus relative myofiber-type distribution. (D) Fatigue index (left) and specific tetanic force (right) of the soleus muscle at the beginning and at the end of the fatigue protocol. (E) Relative Pparb/d and Pgc1a mRNA copy numbers in the TA muscle. (FG) Exercise capacity of C57BL/6J mice treated systemically (i.v) with AAV2/8-myostatinpropeptide or PBS. (F) Effect of AAV2/8-myostatin-propeptide on critical speed before and 6 months after systemic application. (G) The plot depicts the proportional relationship between distance run ( $y$-axis) and time to exhaustion ( $x$-axis) at different velocities. The slope of the regression line indicates the Critical Speed. Values are shown as means \pm SEM. Number (n) of muscles or mice examined: $n=4-6$. 


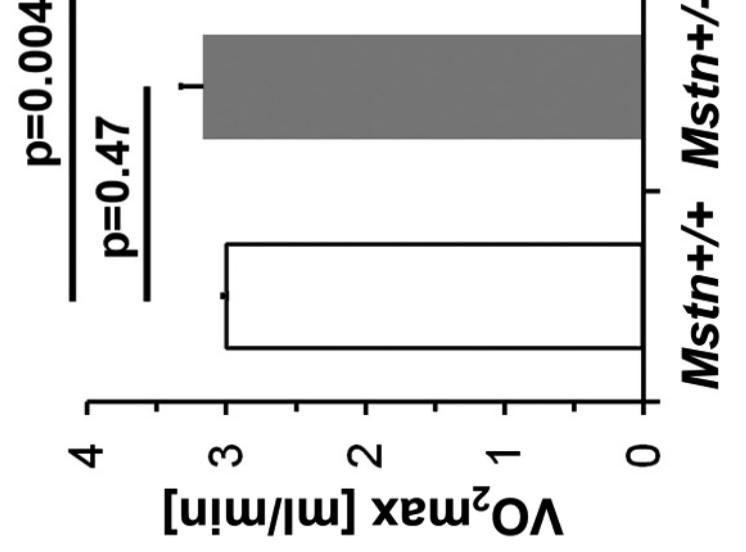

0

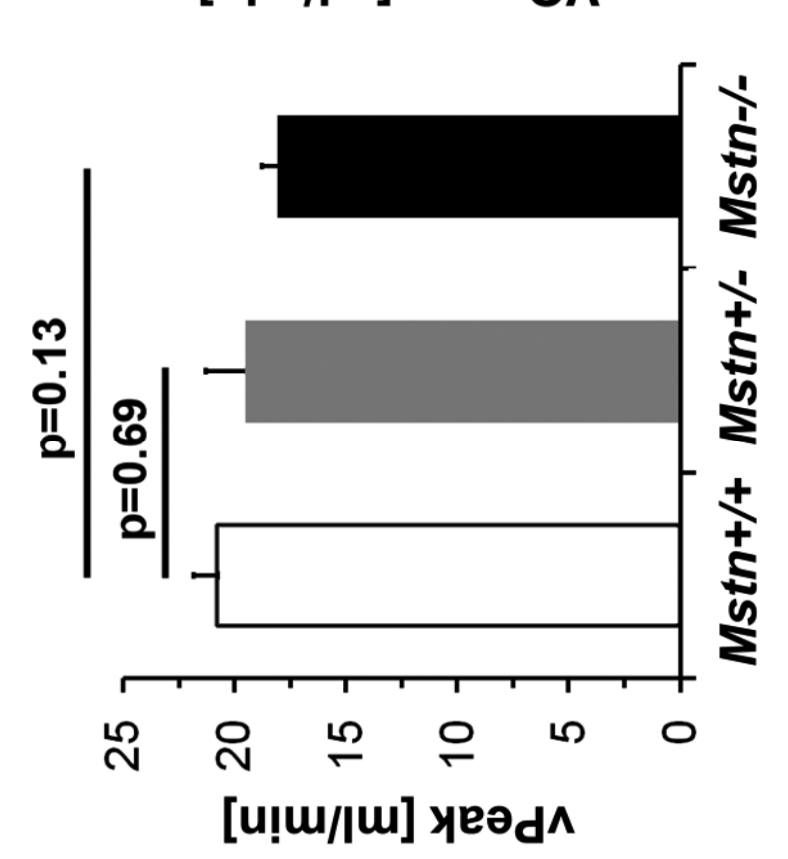

m

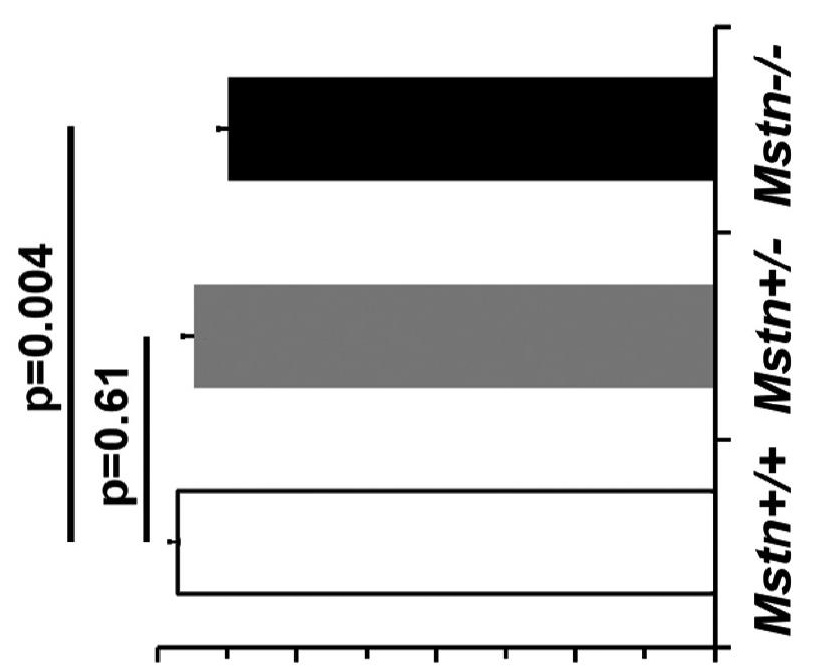

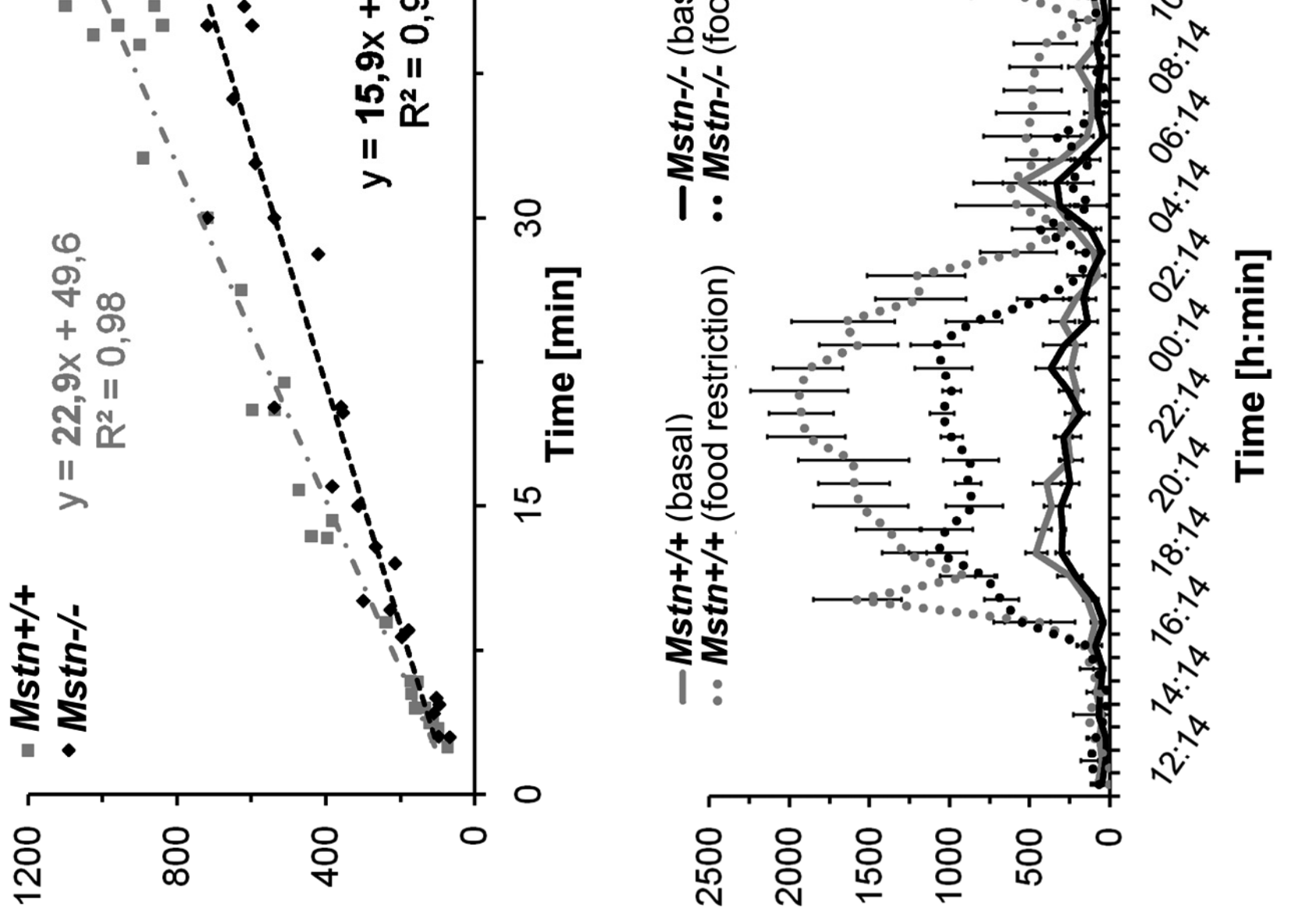

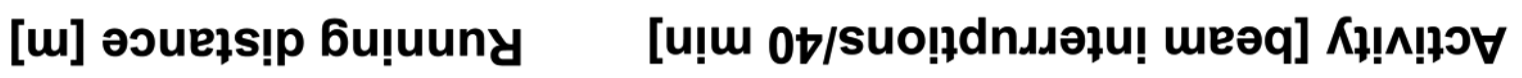

0

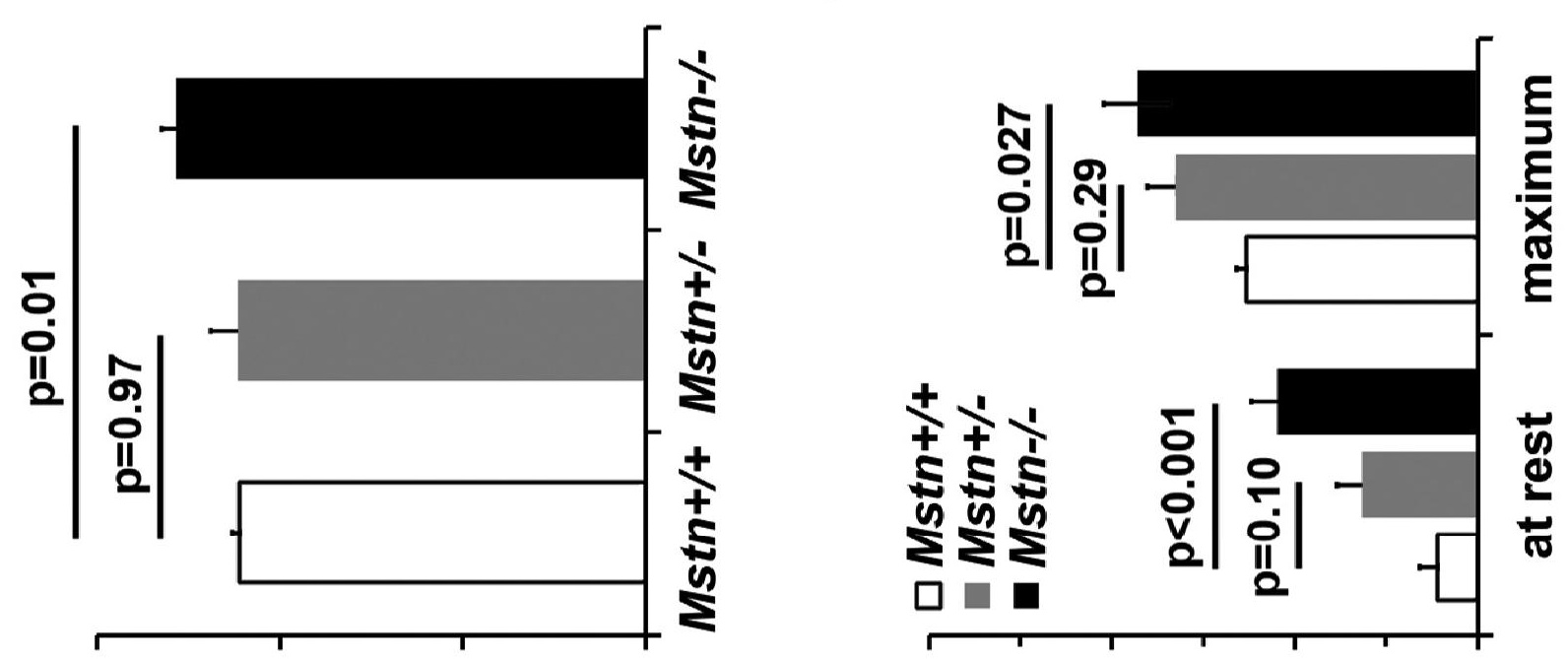


A

B

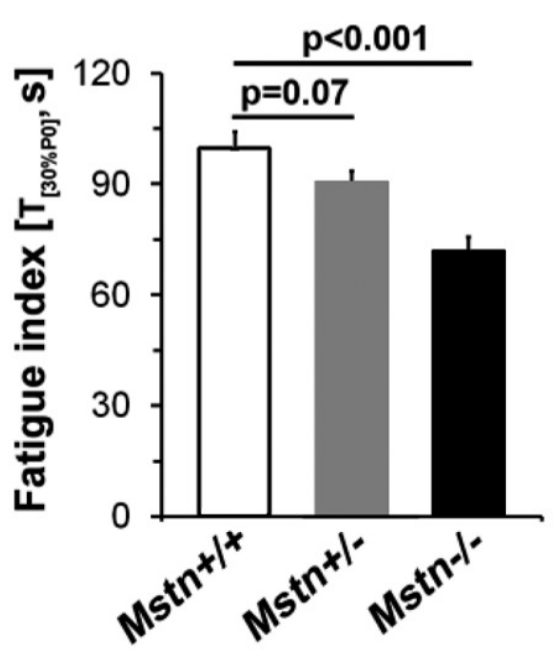

D

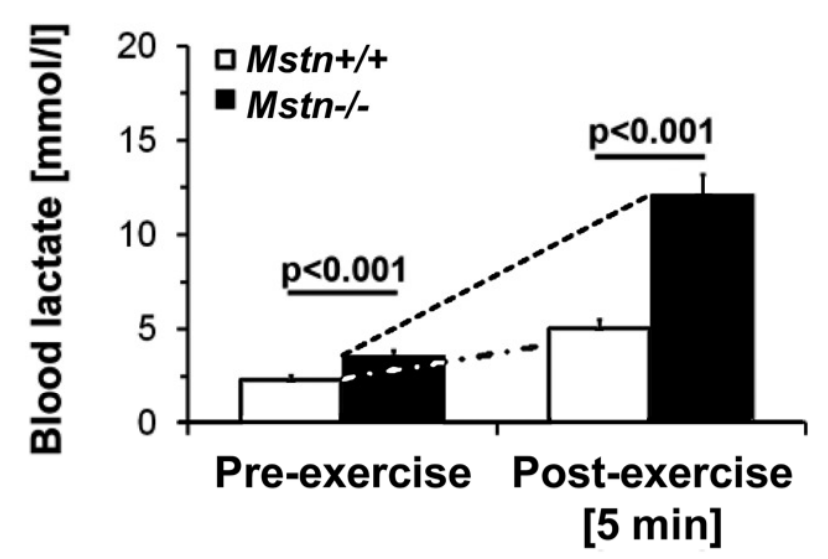

G

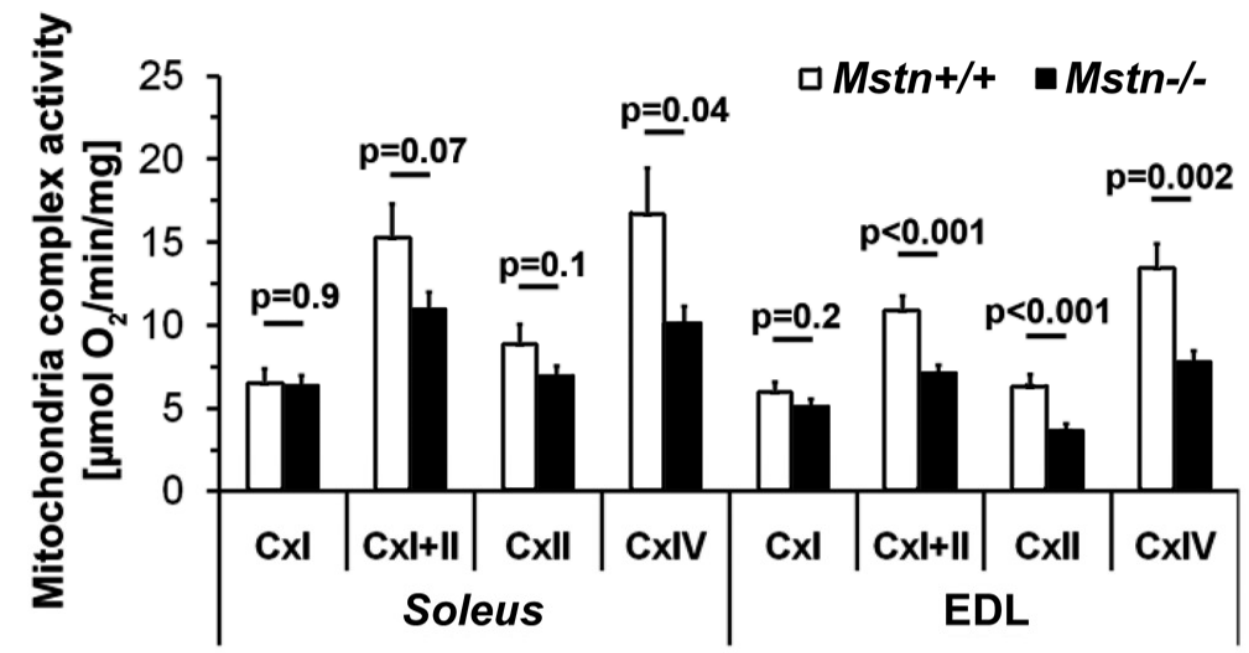

$p<0.05$

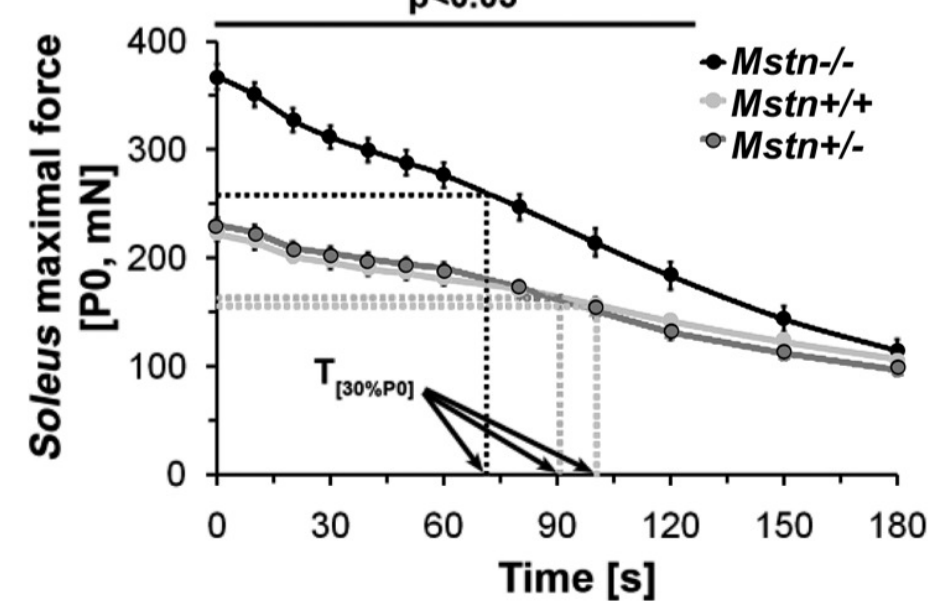

E

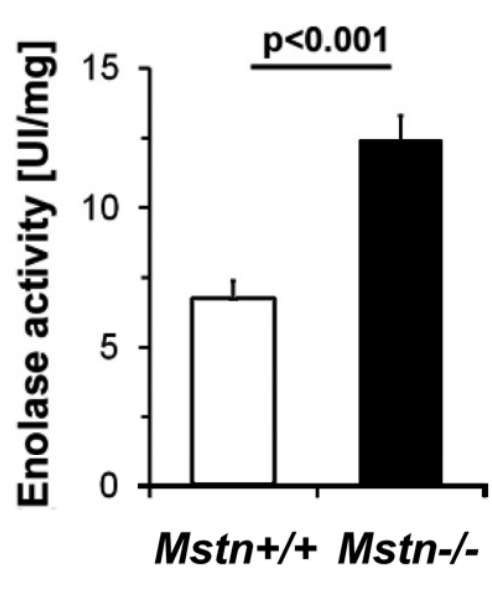

F
C

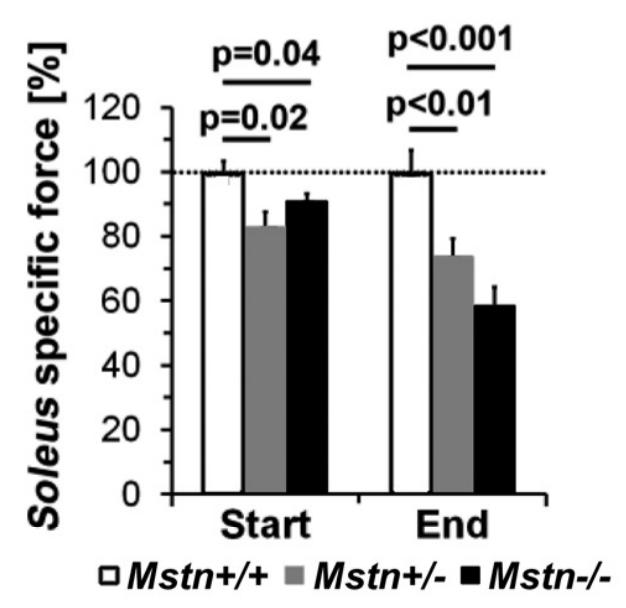

H
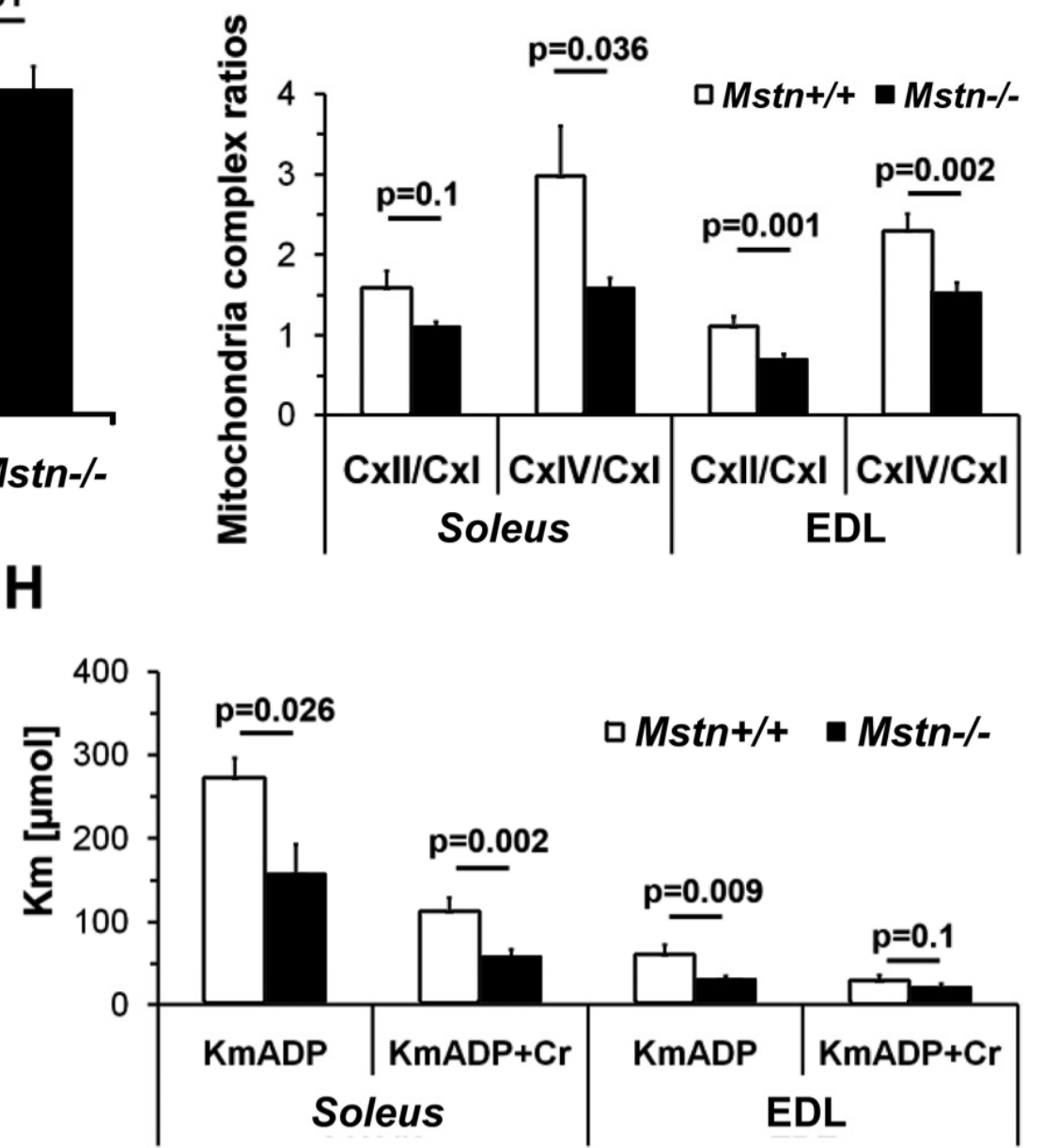


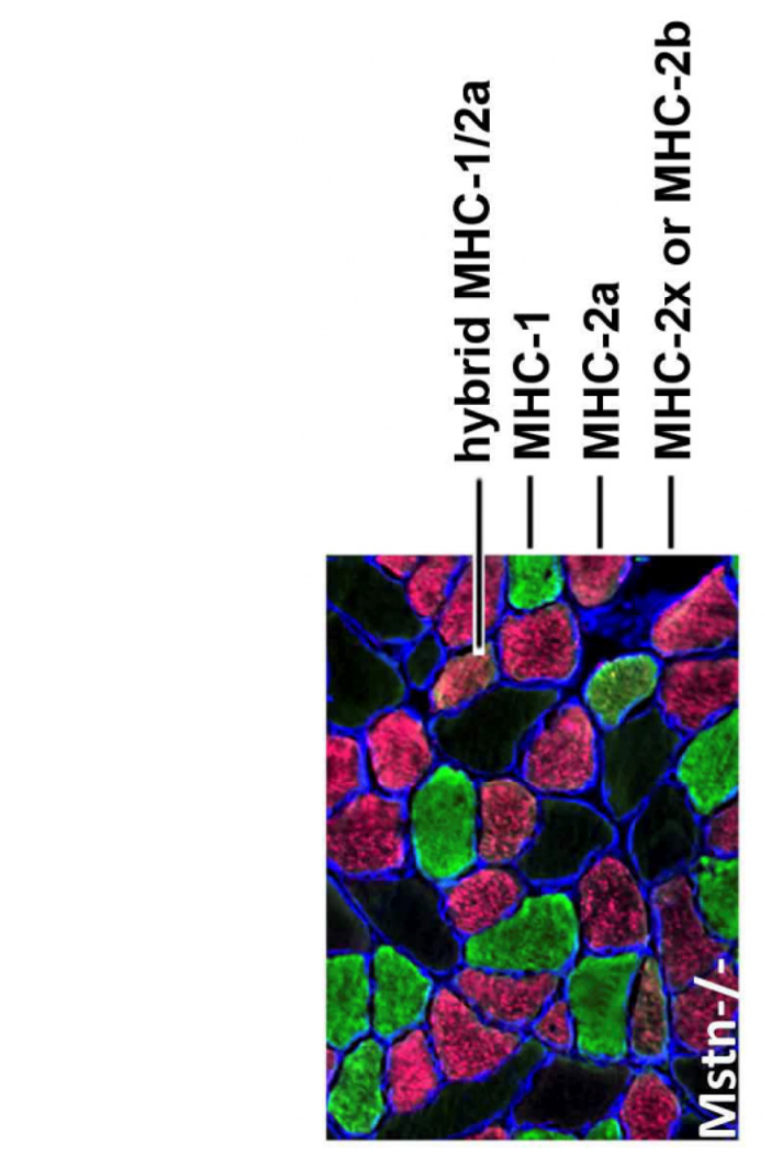

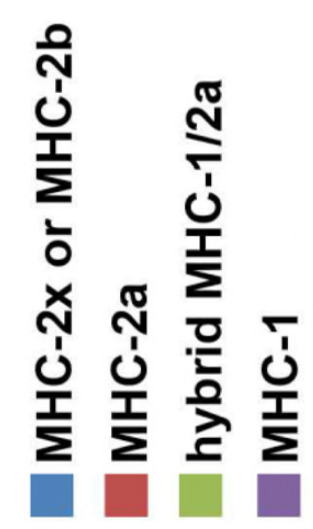

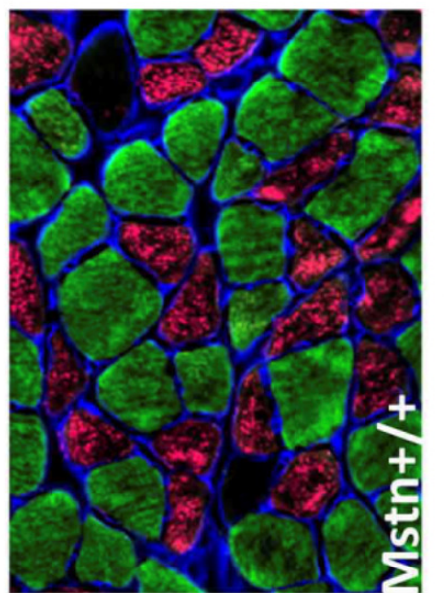

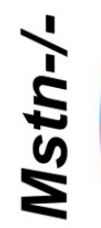

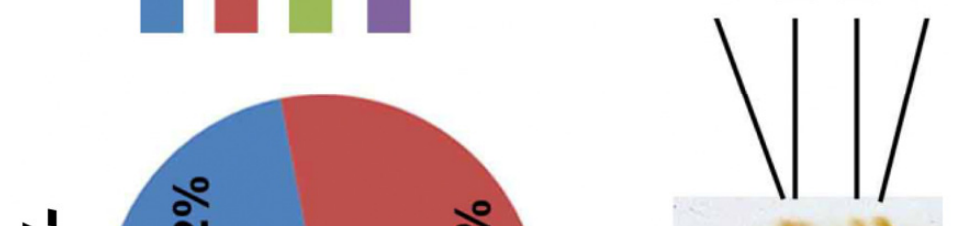

$m$

电

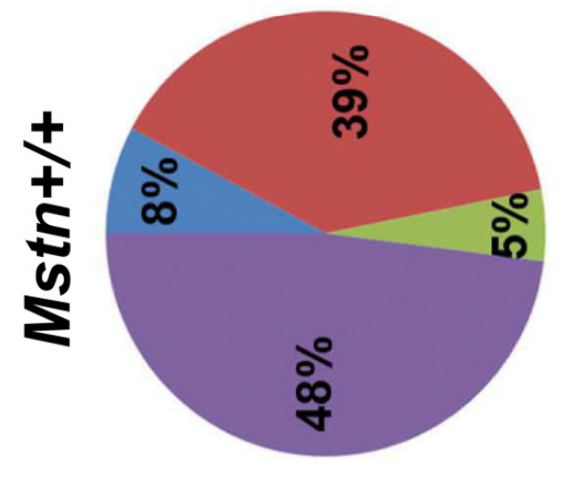

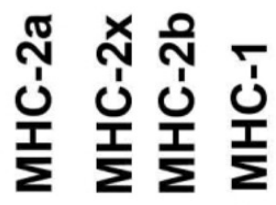

站

Ш

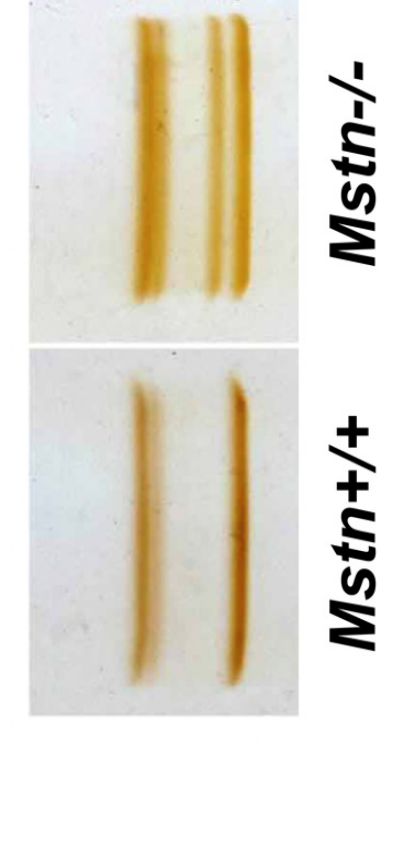

$\stackrel{+}{+}$

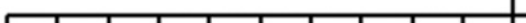

ก 0 म न

İ

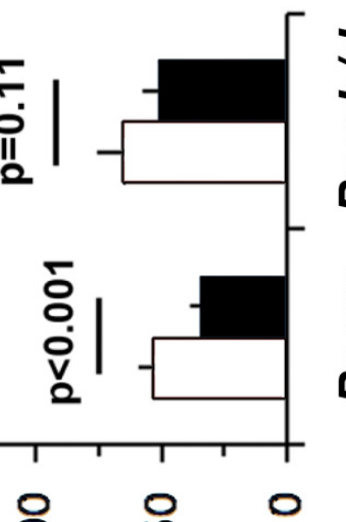

0
$\frac{0}{0}$
$\frac{0}{0}$
$\frac{0}{2}$
$\frac{0}{2}$
$\frac{0}{2}$ $\stackrel{1}{5}$

융 윳 윳

[ $\forall N Y \lambda$ S8I 90 L səqunu Kdos $\forall$ Ny $70 \exists$

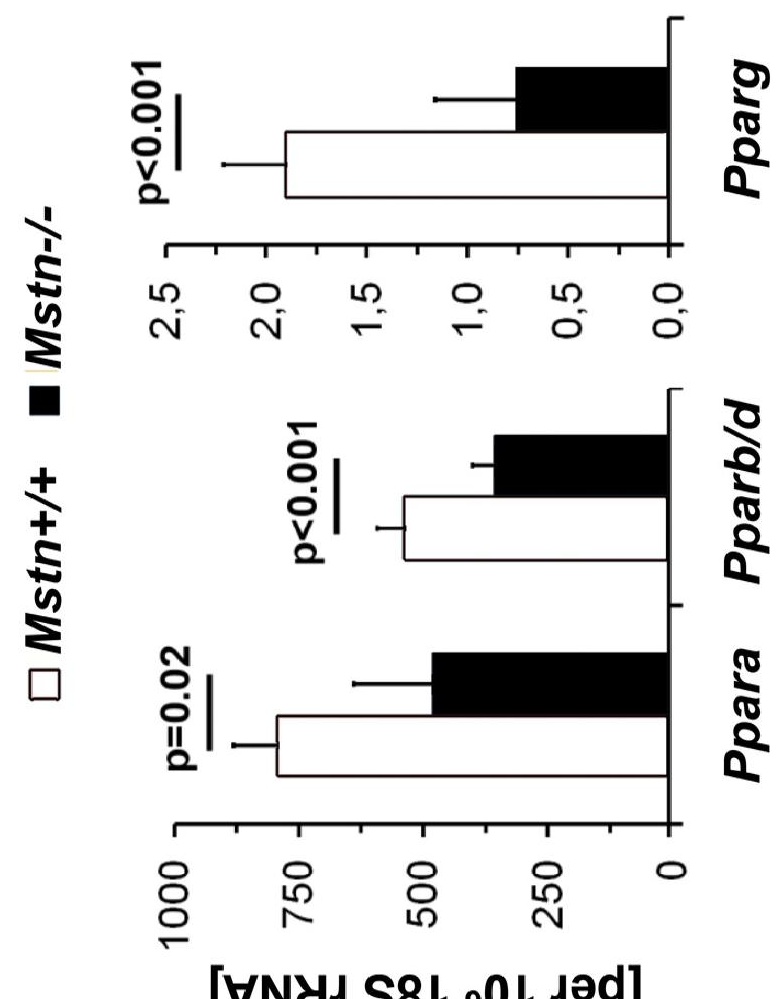




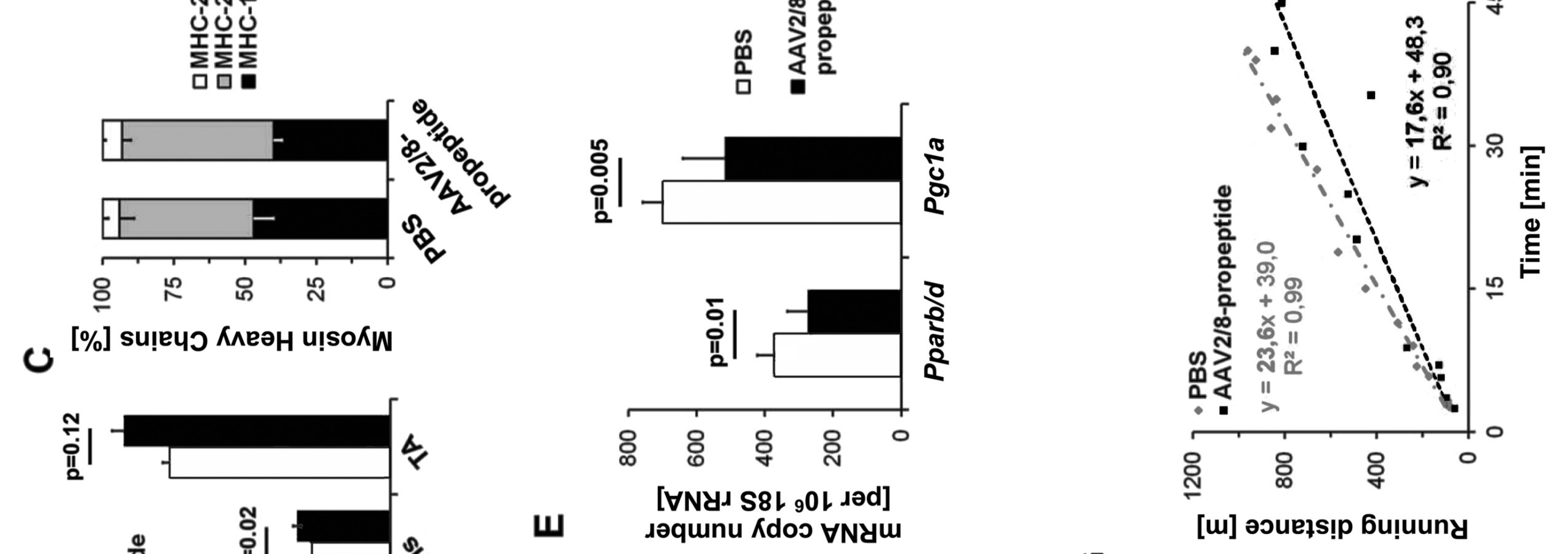

온

$\boldsymbol{m}$
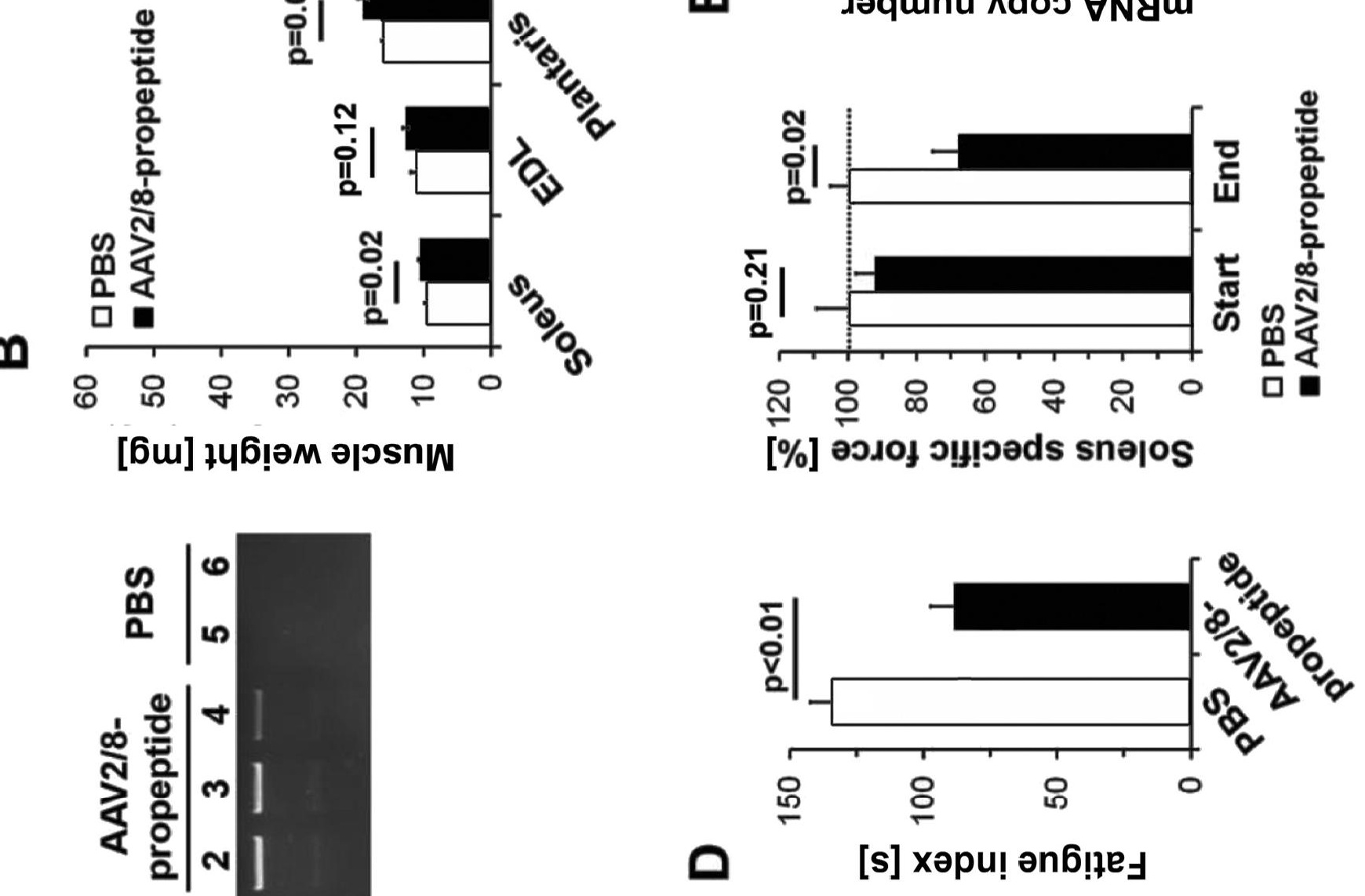

0
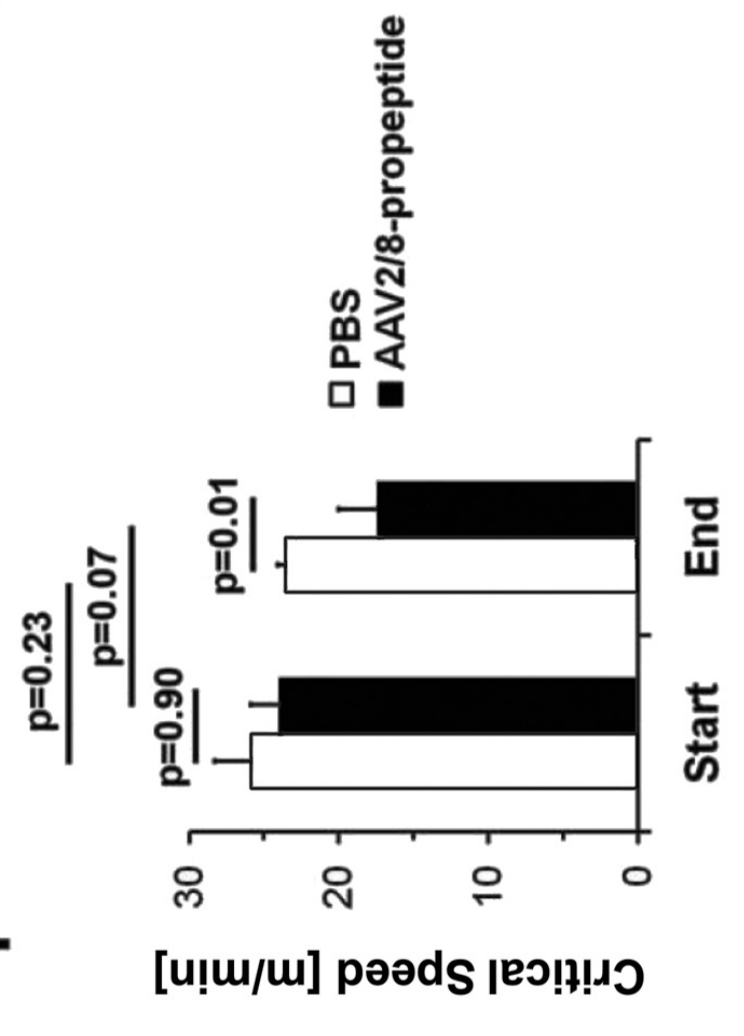